\title{
An Integrated Curvature Surface Inspection and Prediction System for 5-Axis Synchronization Machining
}

Chung-Feng Jeffrey Kuo ( $\sim$ jeffreykuo@mail.ntust.edu.tw )

National Taiwan University of Science and Technology

Wei-Han Weng

National Taiwan University of Science and Technology

\section{Research Article}

Keywords: surface inspection and prediction system, image processing, machine learning, jerk, synchronization machining

Posted Date: February 24th, 2021

DOI: https://doi.org/10.21203/rs.3.rs-234110/v1

License: (c) (i) This work is licensed under a Creative Commons Attribution 4.0 International License.

Read Full License 


\title{
An integrated curvature surface inspection and prediction system for 5-axis synchronization machining
}

\author{
Chung-Feng Jeffrey Kuo*, Wei-Han Weng
}

Department of Materials Science and Engineering, National Taiwan University of Science and Technology, Taipei 10607, Taiwan, ROC

*Corresponding author, E-mail addresses: jeffreykuo@mail.ntust.edu.tw (C.-F. Jeffrey Kuo)

\begin{abstract}
There is an urgent demand for free form products in industry at the present time because of their superior appearance and the wide variety of functions they perform. Five-axis high-speed CNC machining technology has developed to satisfy this demand, but further improvement in surface quality metric inspection technology is the big challenge it now faces. In this study, the effects of jerk on the performance of five-axis synchronous high-speed CNC ball nose end mills on a freeform turbine mold were investigated. The relationships of characteristics of the images of 14 jerk-cluster finished workpieces with different jerk setting values were established, allowing surface texture features to be analyzed and surface roughness predicted. In addition, machine learning methods were integrated with the surface feature analysis to construct a virtual machining module that acts as a performance prediction system, merging the virtual machine tool functions, surface texture processor and AI roughness prediction processor. Using the geometric information of the workpiece, cutting parameters and machine tool parameters as inputs, product performance metrics combining surface roughness and machining time can be predicted as outputs of the system. The integrated system provides users with a way to evaluate manufacturing performance before performing actual operations and to reduce test time for cutting parameter development. The model is suitable for complex surface finishes as well as for the production of small batches with high parametric variance. In addition, the partial set of image processing and roughness prediction modules can be used alone as an effective intelligent surface quality inspection system.
\end{abstract}

Keywords: surface inspection and prediction system, image processing, machine learning, jerk, synchronization machining

\section{Introduction}

There are two main practical problems that engineers face in the manufacturing process: to determine the values of the process parameters that will yield the desired product quality $[1,2]$ and to maximize manufacturing system performance using the available resources $[3,4]$. With respect to the latter, industry nowadays has entered into a phase that focuses on customized, small batches and high parametric variance production, pursued alongside traditional mass-production. Therefore, the inspection of the finished product can no longer be carried out individually on a case-by-case basis, but must be replaced by simple generalized methods that are flexible and can be completed quickly.

As part of the product development flow and manufacturing process chain, as shown 
in Fig. 1, workpiece geometry can be parametrically defined in CAD/CAM computer code, and the tool path can also be generated for given dimensions of a tool according to the desired sequences of machining. The engineer is responsible for selecting tools, feedrates, and speeds to generate the tool paths according to the process planning strategy for the kinematic machining operation [5]. The dynamic accuracy of machine tools is determined by the feed-axis acceleration required to produce precise movement between the workpiece and tool $[6,7]$.

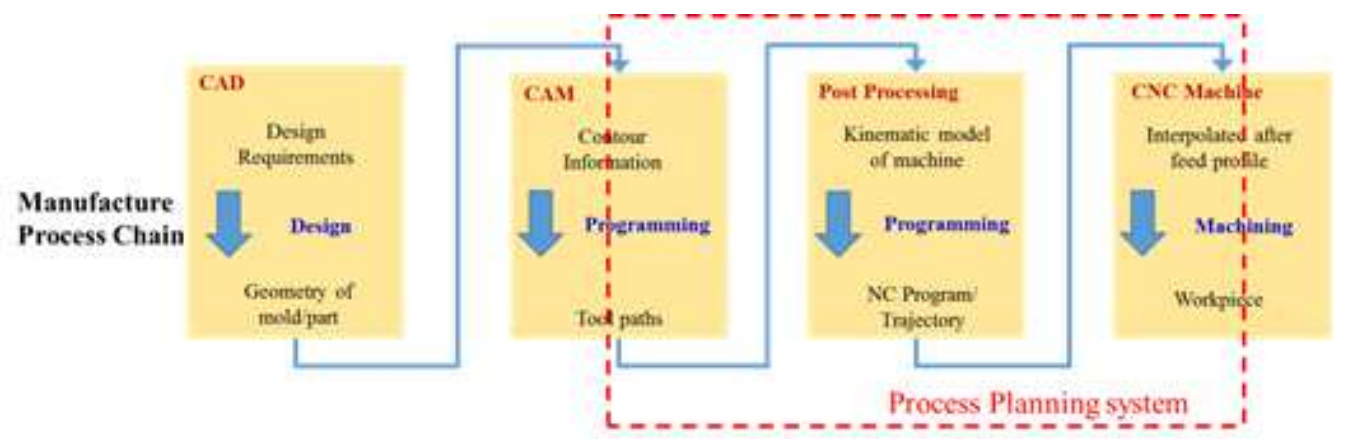

Fig. 1. Product development flow and manufacturing process chain diagram [7]

The purpose of free-form surface machining is to perform the cutting of complex shapes to a given level of quality and to meet that level of quality while minimizing machining time, particularly in the aerospace and automobile industry $[8,9]$. There is literature focusing on speed optimization for machining, and there it is pointed out that jerk settings have a significant impact on machining time as well as the quality of the machining, especially for multi-axis machining applications [10,11]. Barre et al. [12] concluded that jerk selection could have a significant effect on vibration amplitude as well as time of movement. Zhang et al. [13] noted that frequent acceleration and deceleration leads to reduced machining efficiency and the acceleration and impact oscillation that is produced also eventually results in severe vibration and poorer surface textures. Tulsyan and Altintas [14] pointed out while the five-axis CNC machine tool follows the sequence tool path command, the driving parts have velocity, acceleration and jerk discontinuities at transition points, and these discontinuities lead to poor surface quality. From these studies, it can be seen the jerk values assigned to a job have a relationship with the surface quality of the result. And, the errors caused by CNC machine motion will be projected onto the machined surface, especially important in the machining of molds and dies [15].

Surface roughness inspection is an essential quality control process undertaken to ensure that parts are manufactured to a specific requirement [16,17]. However, measuring the surface quality of a free form mold poses a big challenge, even when the jerk setting and its effect is known. Since the process mechanisms determining surface quality are composed of numerous uncontrollable and nonlinear factors, an accurate predictive model is needed [18]. Using texture analysis techniques, texture parameters could provide the data to evaluate surface roughness by means of various predictive modeling methods. With the growing demand for industrial automation in the manufacturing sector, machine vision plays an important role in quality inspection and process monitoring [19]. Many researchers have used image recognition technology to classify surfaces [20]. Cuka et al. [21] developed a vision-based end-milling metal surface roughness evaluation system that could perform surface texture evaluation. Joshi and Patil [22] have reviewed recent advances in machine vision-based evaluation 
of surface roughness using texture analysis techniques and predictive modeling.

Machine learning has advanced rapidly not only in terms of research results but also in terms of usability, as it promises to answer many new manufacturing challenges $[23,24]$. Some scholars combine these newly developed technologies to model and predict surface roughness [25]. Zhu and Brilakis [26] developed an artificial neural network (ANN) model for analyzing and predicting the relationship between cutting conditions and fractal parameters of the corresponding machined surface to obtain specific surface roughness profile geometries. Asiltürk and Çunkaş [27] used multiple regression and artificial neural network approaches to predict surface roughness and concluded that ANN is a powerful tool with high accuracy compared to multiple regression. Patel et al. [28] used the gray level co-occurrence matrix (GLCM) to extract graphic texture characteristics of the end milling surface. On the basis of their experimental results, the authors suggested using machine learning algorithms to extract features from the GLCM has potential industrial applications. Morala-Argüello et al. [29] proposed the use of a multi-resolution method based on surface image processing for visual quality inspection and surface roughness identification during turning. The error rate of the proposed method was between $2.59 \%$ and $4.17 \%$. Özel and Karpat [30] used neural network modeling to predict surface roughness and tool blade wear during the entire machining process under various cutting conditions when completing with hard turning. Compared with the regression model, they found that the predictive neural network model could better predict surface roughness within its training range. Zain et al. [31] proposed an ANN model for predicting surface roughness performance during processing. Their research results showed that the most influential decision-making variables were cutting speed, feed rate and cutting depth. This study also proved that using available experimental data, accurate predictive performance metrics can be obtained through a small number of training and testing sessions. Ramesh et al. [32] used Support Vector Machine (SVM) methods to predict the surface roughness of end mills on 6061 aluminum. Using feed speed, spindle speed, and cutting depth as input to predict surface roughness, the model had an error rate of 8.34\%. Kayabaşi and Ertürk [33], adopting an experimental design with the four variables of cutting speed, feed per tooth, cutting part and cutting width and using three-axis vibration signals as input, developed a probabilistic real-time surface roughness prediction system, with an accuracy rate as high as $96.37 \%$

After reviewing the literature, it can be seen machine learning methods incorporating image recognition can successfully build predictive models of surface roughness which are of great practical use and which are adaptable for use in different applications. However, most of this research has focused on plain machining techniques, such as turning or milling. In free-form mold surfaces that are milled by a high speed five-axis machine tool, it is a critical issue to measure the roughness of all regions due to their complex and varied curvature topology characteristics. Thus, the purpose of this study is to develop an approach that could be used to predict manufacturing system performance (roughness and machining time) for various surfaces where cutting parameters are affected by axis synchronization due to jerk selection.

\section{Methodology \& method}

\subsection{Analysis of the manufacturing process}

A diagram depicting the organization of the study's manufacturing process analysis and the relationship between the input/output and activity components is shown in Fig. 
2. To overcome the challenge of system development, the process was split into two parts:

Part 1: Surface texture feature \& roughness prediction. The strategy was to get image texture features of the workpiece first, and then to build a surface roughness prediction processor.

Part 2: Virtual machine tool \& surface texture. For wide application, the prediction system also developed a virtual machine tool module to simulate machine processing with total machine time and surface texture feature prediction as outputs.

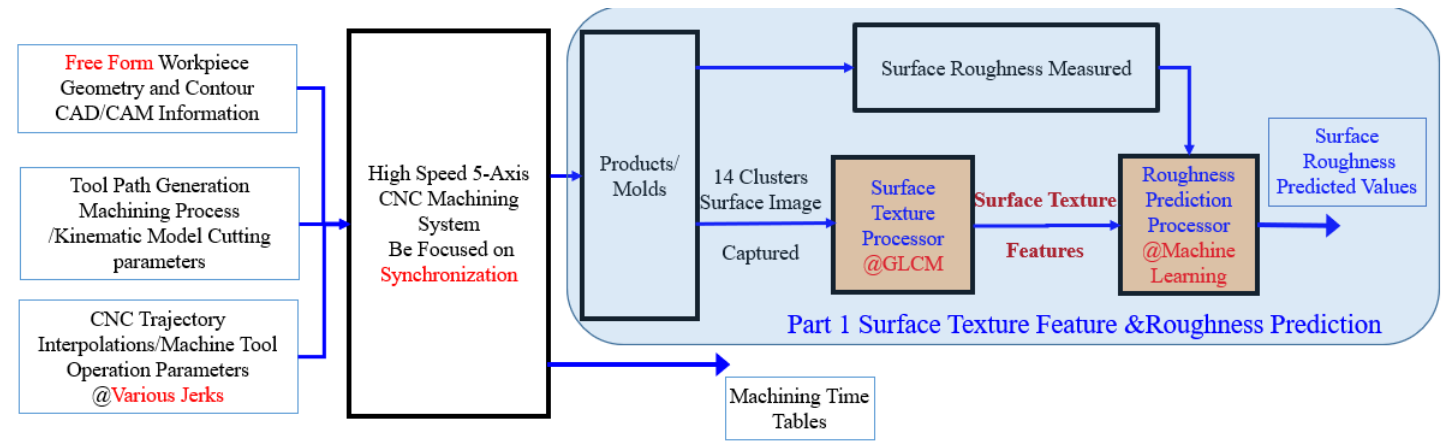

Fig. 2(a) Manufacturing Process Flow Diagram of Part 1

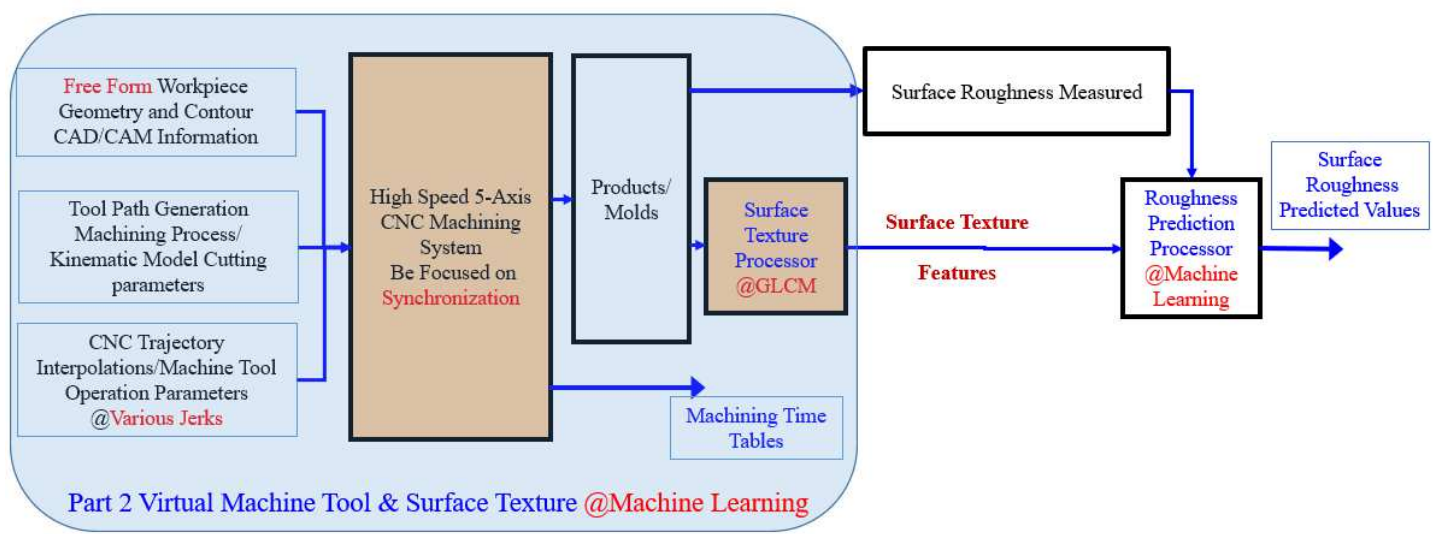

Fig. 2(b) Manufacturing Process Flow Diagram of Part 2

\subsection{Prediction kernel function development}

Machine learning and statistical analysis methods were introduced to build modules with non-linear kernel functions, as seen in the manufacturing process diagram (Fig. 2).

(1) Artificial Neural Network (ANN) architecture [31,34]

Compared with traditional complex modeling techniques, neural network systems provide a more advanced way to analyze data through training. A neural network architecture is often used in prediction, control, system identification, model building, medicine, and computer vision systems. Artificial neural networks use nonlinear functions as learning kernels, with the weighted output of multiple neurons feeding into further layers. The multi-layer networks are connected in sequence to increase learning accuracy. An example of a single layer neuron architecture is shown in Fig. 3: 


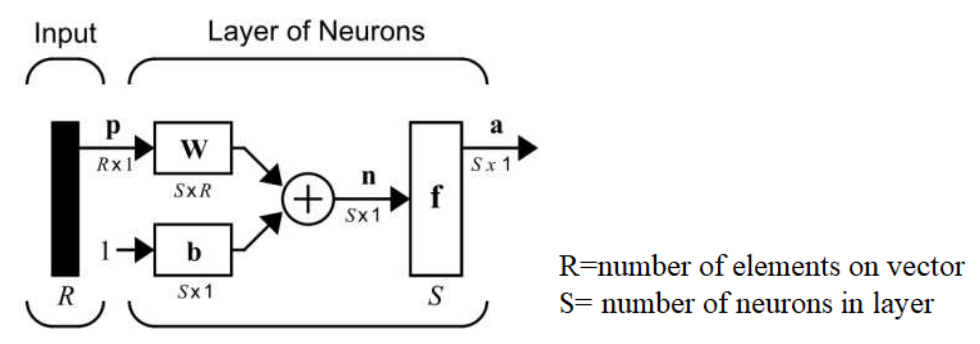

Fig. 3. A single neuron layer [35]

Each neuron received total input from the sum of the previous layers as

$$
a=f(w p+b)
$$

where $p$ is the multiplication operations with $\mathrm{R}$ length input vector, $w$ is the weight matrix with size SxR, while $b$ and $a$ are the bias vector and output respectively with S length.

Since neural networks are nonlinear by nature and consist of multiple inputs and multiple outputs, they are suitable to model complex nonlinear systems. In this study, we use these principles to establish the textural features of the surface pattern obtained from the input of the cutting conditions and also to estimate the surface profile, established from texture features. In addition to these model outputs, the actual machining time can also be modeled in the same way so that a predictive model of the time taken is obtained after training of the input machining conditions and parameters.

(2) The image processing module

The purpose of the image processing module is to extract the characteristics of the workpiece surface and establish the relationship between image characteristics and surface roughness. To analyze the detailed information and the texture provided by images, a Gray-Level Co-Occurrence Matrix (GLCM) was used to quantitatively evaluate textural parameters. The definition of GLCM is described in [36]. The cutting mechanism leaves tool marks (scallops and cusps) on the workpiece surface [37], and these marks, of varying heights, are perhaps the most significant source of information for texture analysis. From basic optic principles, the bright areas correspond to light reflected from the geometric shapes, representing surface roughness patterns or features. In order to allow detailed classification, we used deep learning to observe the final results and obtain useful analysis results. A 56-layer ResNet architecture convolutional neural network (CNN) developed in Python v3 on Google colaboratory was used to train and classify different images in four workspace regions with a classification accuracy of $93.35 \%$.

In review, a tool leaves markings on the surface after machining, the relevant feature of which is a texture composed of scallops and cusps, which is experienced as surface roughness. And if a cutting parameter is inappropriately set, it can lead to unsynchronized machining and poor surfaces. Visualizing results with Grad-CAM and heat-maps allows some distinctive features to be observed:

(1) Because the tool used for cutting is a ball-end mill tool, the surface traces it leaves may be characterized by symmetry. If the surface shows more symmetric traces, it indicates this combination of parameters is suitable. Fig. 4 reproduces some images 
in zone1 where this phenomenon could be observed.
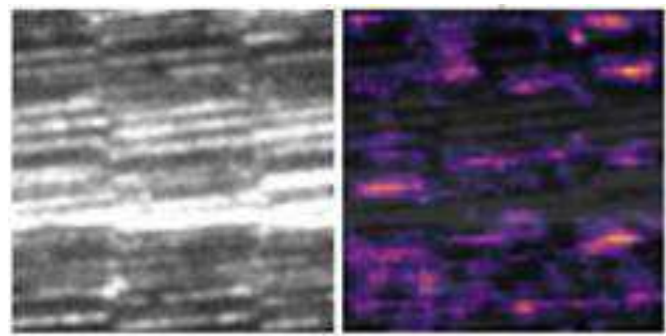

(a) A sample with $2.180 \mu \mathrm{m}$ roughness
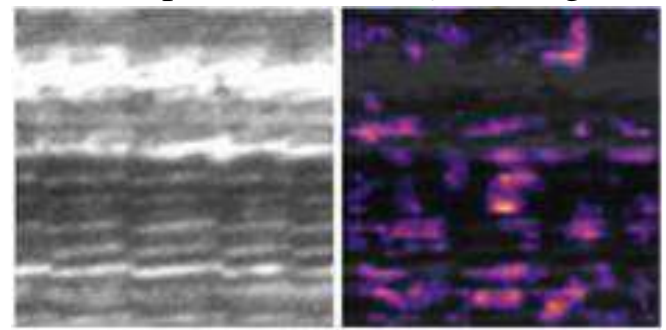

(c) A sample with $2.317 \mu \mathrm{m}$ roughness
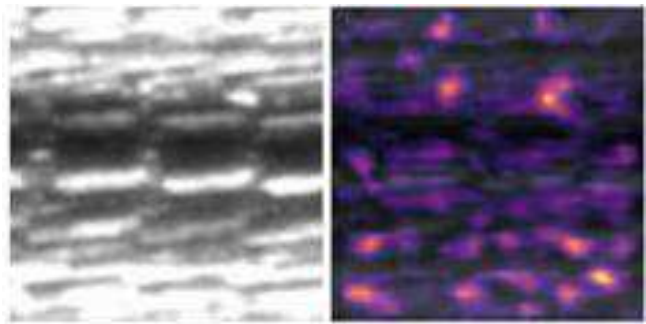

(b) A sample with $2.399 \mu \mathrm{m}$ roughness
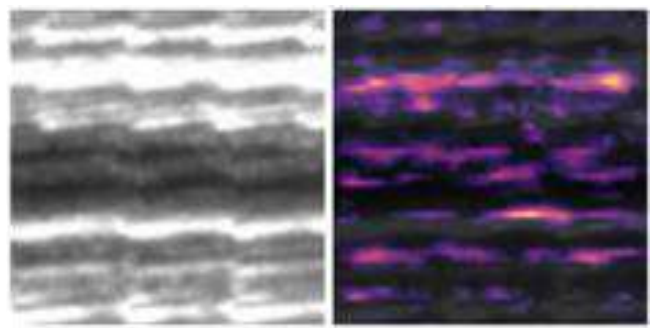

(d) A sample with $2.333 \mu \mathrm{m}$ roughness

Fig.4. Some surface images with heat-map results in zone1

(2) When the surface trace has obvious and uniform light and dark distributions, it means that the tool is processing on a good match. If the axial match is not good, the residual traces of the tool will appear asymmetrical, or will not be able to maintain a uniform state. Fig. 5 shows some images in zone 2 where this phenomenon could be observed.
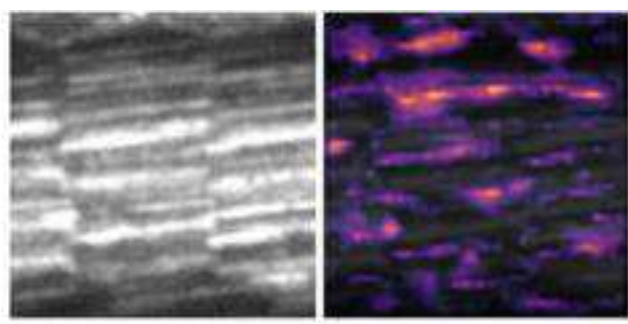

(a) A sample with $2.137 \mu \mathrm{m}$ roughness
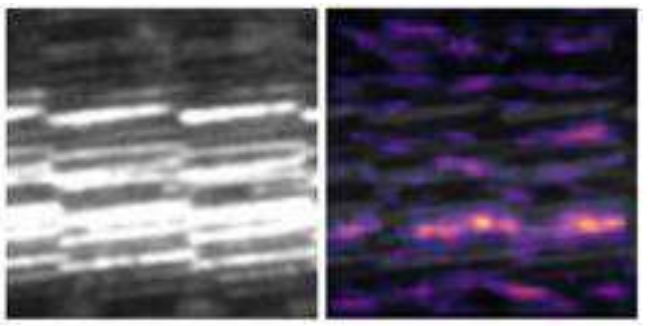

(c) A sample with $2.317 \mu$ m roughness
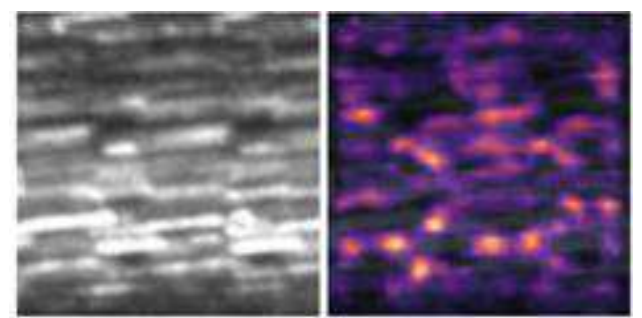

(b) A sample with $2.445 \mu \mathrm{m}$ roughness
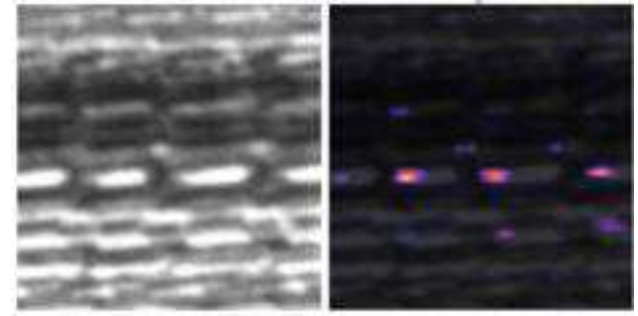

(d) A sample with $2.333 \mu \mathrm{m}$ roughness

Fig. 5. Some surface images with heat-map results in zone2

(3) Another phenomenon characteristic of poor matching is the lack of long continuous streaks. When processing curved workpieces, the tool will maintain a fixed angle with the surface tangent, so the trace will be discontinuous in areas where the curvature changes. When the shaft is not well matched, the tool cannot maintain a fixed angle with the cutting table and will offset, which means the tool will be too 
deep to produce a continuous trace. Fig. 6 shows an example of this phenomenon. The red rectangle indicates where a connected line of quiescent points appears.

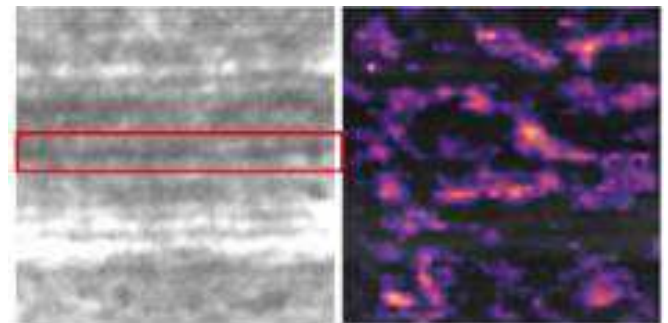

(a) A sample with $2.193 \mu \mathrm{m}$ roughness

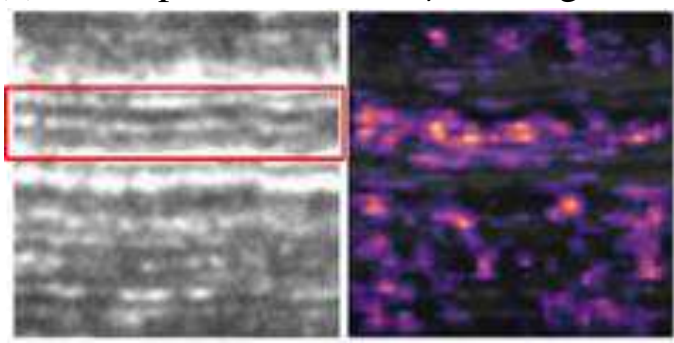

(c) A sample with $2.313 \mu \mathrm{m}$ roughness
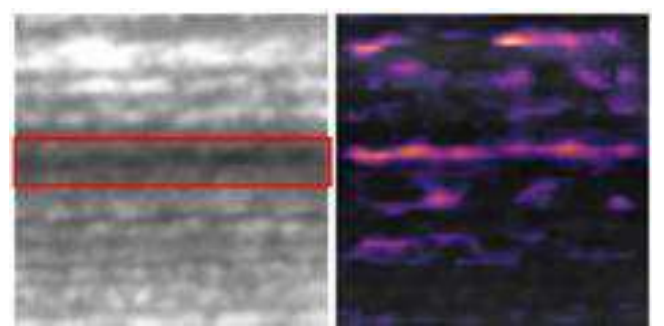

(b) A sample with $2.393 \mu$ m roughness
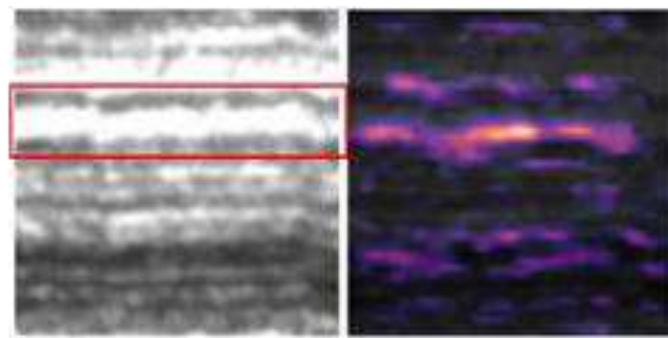

(d) A sample with $2.360 \mu \mathrm{m}$ roughness

Fig. 6. Some surface images with heat-map results in zone3 and zone 4

To more clearly classify these images, the gray level would be an important factor in a module distinguishing the above features. Therefore, the color model adopted is the HSV model, not grayscale, since it provides a value for brightness, which is used as input to the module, for the combination of six textural features selected for study.

To get texture information, let $p(i, j)$ be the $(i, j)$ th entry in a GLCM having $N_{x}$ columns and $N_{y}$ rows. $N g$ stands for the number of levels of pixel. The mean and standard deviations for the row and columns of the matrix are shown below as Eq. (2) and (3):

$$
\begin{gathered}
\mu_{x}=\sum \sum i \cdot p(i, j), \mu_{y}=\sum \sum j \cdot p(i, j) \\
\sigma_{x}=\sum \sum\left(i-\mu_{x}\right)^{2} \cdot p(i, j), \sigma_{y}=\sum \sum\left(i-\mu_{x}\right)^{y} \cdot p(i, j)
\end{gathered}
$$

Following are the six features, defined in Eq.(4) to (9). These surface texture features contain unique machining characteristics and are used as the input to the roughness prediction processor.

(a) Correlation [36,38]:

$$
f_{1}=\sum_{i=1}^{N_{g}} \sum_{j=1}^{N_{g}} \frac{(i j) p(i, j)-\mu_{x} \mu_{y}}{\sigma_{x} \sigma_{y}}
$$

(b) Energy

$$
f_{2}=\sum_{i=1}^{N_{g}} \sum_{j=1}^{N_{g}}\|p(i, j)-\bar{p}(i, j)\|^{2}
$$


where $\bar{p}(i, j)$ is the average of $p(i, j)$

(c) Homogeneity [38]

$$
f_{3}=\sum_{i=1}^{N_{g}} \sum_{j=1}^{N_{g}} \frac{1}{1+(i-j)^{2}} p(i, j)
$$

(d) Sum entropy [36]

$$
f_{4}=-\sum_{i=2}^{2 N_{g}} p_{x+y}(i) \log \left(p_{x+y}(\mathrm{i})\right)
$$

(e) Sum variance [36]

$$
f_{5}=\sum_{i=2}^{2 N g}\left(i-f_{4}\right)^{2} p_{x+y}(i)
$$

(f) Information measure of correlation [36]

$$
f_{6}=\sqrt{1-e^{-2(H X Y 1-H X Y)}}
$$

where $H X Y=-\sum_{i} \sum_{j} p(i, j) \log (p(i, j))$,

$$
H X Y 1=-\sum_{i} \sum_{j} p_{x}(i) p_{y}(j) \log \left(p_{x}(i) p_{y}(j)\right)
$$

\section{Experiment \& discussion}

\subsection{Experiment equipment and device}

The purpose of this experiment was to evaluate the concept described in section 2.2, that is, the development of a prediction model. A single turbine vane mold shown in Fig. 7(a) was used for demonstration purposes. It was machined, tested, and verified by means of 5-axis synchronous ball-end milling. To compare the effect of jerk setting for each axis on the roughness of the machined surface, four areas, marked as zone No. 1 to 4, were selected for study. The 5-axis tool machine shown in Fig. 7(b) was a UX300 with Heidenhain controller (iTNC 530) made by Quaser. An area scan camera was selected for capturing the surface image. The equipment used for this experimental test is listed in Table 1. The feed rate and spindle speed were set to a constant of 7,000 $\mathrm{mm} / \mathrm{min}$ and 11,500 rpm respectively. The shape of the cutting tool was assumed to be constant during experimentation. Work on the virtual model, image processing and machine learning development environment took place under Matlab 2018b.

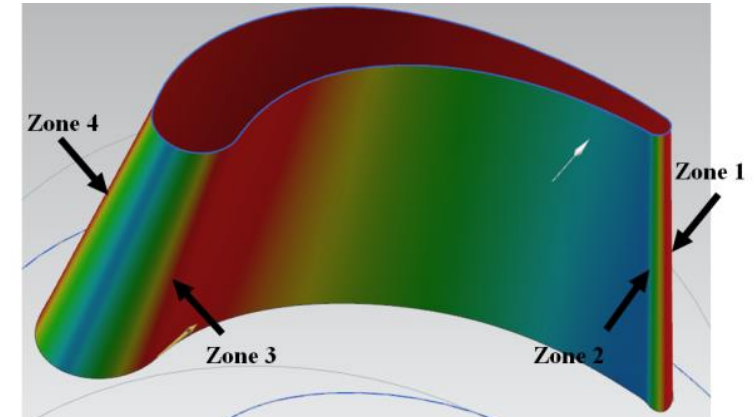

(a) Blade mold, color shows different

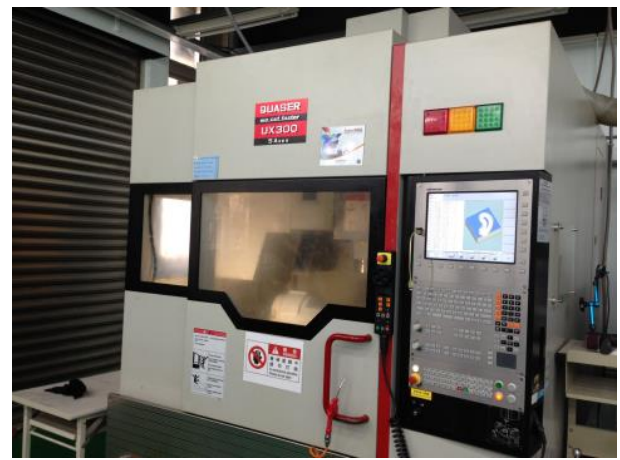

(b) UX-300 
curvatures

Fig. 7. The experiment mold and equipment

Table 1 The equipment information of the experiment

\begin{tabular}{|l|l|l|l|}
\hline Machine & $\begin{array}{l}\text { UX300 (Quaser) with 5 } \\
\text { axes( X,Y,Z,A,C) }\end{array}$ & Controller & iTNC 530 (Heidenhain) \\
\hline $\begin{array}{l}\text { Rapid Traverse } \\
\text { X/Y/Z (mm/min) }\end{array}$ & $36,000 / 36,000 / 32,000$ & $\begin{array}{l}\text { Max. Speed A/C } \\
(\mathrm{rpm})\end{array}$ & $9,000 / 9,000$ \\
\hline Spindle Speed (rpm) & 12,000 & Tool type & Ball-end mill \\
\hline Mold type & single turbine vane & Mold material & 6061 aluminum alloy \\
\hline Machining strategy & Layer-by-layer & Mold dimension & $96 \times 17 \times 25$ mm \\
\hline Camera & acA2500-14gm GigE (Basler) & \\
\hline
\end{tabular}

\subsection{Data prepared}

Since setting the jerk value on each of the five axes to the optimal jerk value for that particular axis does not yield the best surface quality overall, settings on each axis need to be balanced with those on other axes for best performance. For comparison purposes, 14 clusters each with different jerk settings, shown in Table 2, were applied to the machining of the mold. Information about the mold dimensions, from CAM, is represented as the distance between every two set-points, which is the tool path segment. The average path length on each axis is listed in Table 3.

Table 2 The jerk values setting cluster

\begin{tabular}{|c|c|c|c|c|c|}
\hline $\begin{array}{c}\text { Cluster } \\
\text { No. }\end{array}$ & $\begin{array}{c}\mathrm{X} \text {-axis } \\
\left(\mathrm{mm} / \mathrm{s}^{3}\right)\end{array}$ & $\begin{array}{c}\text { Y-axis } \\
\left(\mathrm{mm} / \mathrm{s}^{3}\right)\end{array}$ & $\begin{array}{c}\text { Z-axis } \\
\left(\mathrm{mm} / \mathrm{s}^{3}\right)\end{array}$ & $\begin{array}{c}\text { A-axis } \\
\left(\mathrm{deg} / \mathrm{s}^{3}\right)\end{array}$ & $\begin{array}{c}\text { C-axis } \\
\left(\mathrm{deg} / \mathrm{s}^{3}\right)\end{array}$ \\
\hline 1 & 10,000 & 8,000 & 10,000 & 15,000 & 15,000 \\
\hline 2 & 10,000 & 10,000 & 10,000 & 10,000 & 15,000 \\
\hline 3 & 10,000 & 10,000 & 10,000 & 15,000 & 15,000 \\
\hline 4 & 10,000 & 10,000 & 10,000 & 15,000 & 30,000 \\
\hline 5 & 10,000 & 10,000 & 10,000 & 30,000 & 30,000 \\
\hline 6 & 10,000 & 15,000 & 10,000 & 15,000 & 15,000 \\
\hline 7 & 10,000 & 20,000 & 10,000 & 30,000 & 15,000 \\
\hline 8 & 15,000 & 10,000 & 30,000 & 10,000 & 15,000 \\
\hline 9 & 15,000 & 15,000 & 10,000 & 10,000 & 30,000 \\
\hline 10 & 20,000 & 10,000 & 10,000 & 15,000 & 15,000 \\
\hline 11 & 20,000 & 10,000 & 10,000 & 30,000 & 30,000 \\
\hline
\end{tabular}




\begin{tabular}{|c|c|c|c|c|c|}
\hline 12 & 20,000 & 20,000 & 10,000 & 10,000 & 10,000 \\
\hline 13 & 20,000 & 20,000 & 10,000 & 30,000 & 30,000 \\
\hline 14 & 30,000 & 30,000 & 30,000 & 30,000 & 30,000 \\
\hline
\end{tabular}

Table 3 Mold information - axis average path length

\begin{tabular}{|c|c|c|c|c|}
\hline Item & Zone 1 & Zone 2 & Zone 3 & Zone 4 \\
\hline X-axis (mm) & 0.0257 & 0.0375 & 0.0316 & 0.0859 \\
\hline Y-axis (mm) & 0.0091 & 0.0400 & 0.0445 & 0.0886 \\
\hline Z-axis (mm) & 0.0013 & 0.0016 & 0.0013 & 0.0014 \\
\hline A-axis (deg) & 0.0647 & 0.0667 & 0.0744 & 0.0602 \\
\hline C-axis (deg) & 0.4737 & 4.002 & 0.6106 & 5.0962 \\
\hline
\end{tabular}

\subsection{Virtual model development}

The virtual machining model development, combining machine learning and image processing, consisted of three parts:

(a) Image texture prediction model,

(b) Roughness prediction model, and

(c) Machining time estimation model.

Firstly, the subtle surface texture differences generated by unsynchronized motion at different jerk values were verified to be recognizable by machine learning and image processing techniques. Since the curvature zones were expected to have different features, a pre-classified filter was developed to increase prediction accuracy. A total of 2520 surface images obtained from the 4 different zones were used as input for classification, along with the six textural features noted in the previous section 2.2. A confusion matrix of the classified results is shown in Fig. 8. A total accuracy of $99.5 \%$ was gained from the Support Vector Machine (SVM) [39] validation.

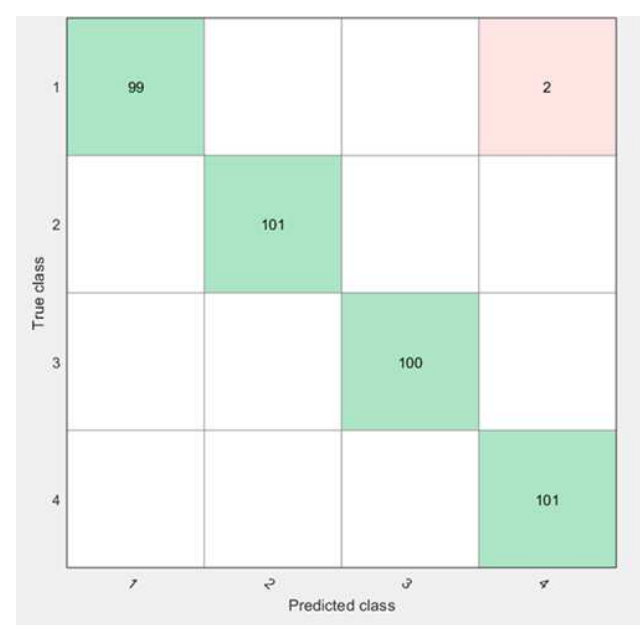

Fig. 8. The SVM classified result 
Convolutional Neural Networks (CNN) [40] are very useful in the classification and recognition of images. The results of the CNN classification of the present study, as seen in Table 4, show that there are indeed unique features in the images that can be used as a basis for classification.

Table 4 The CNN results

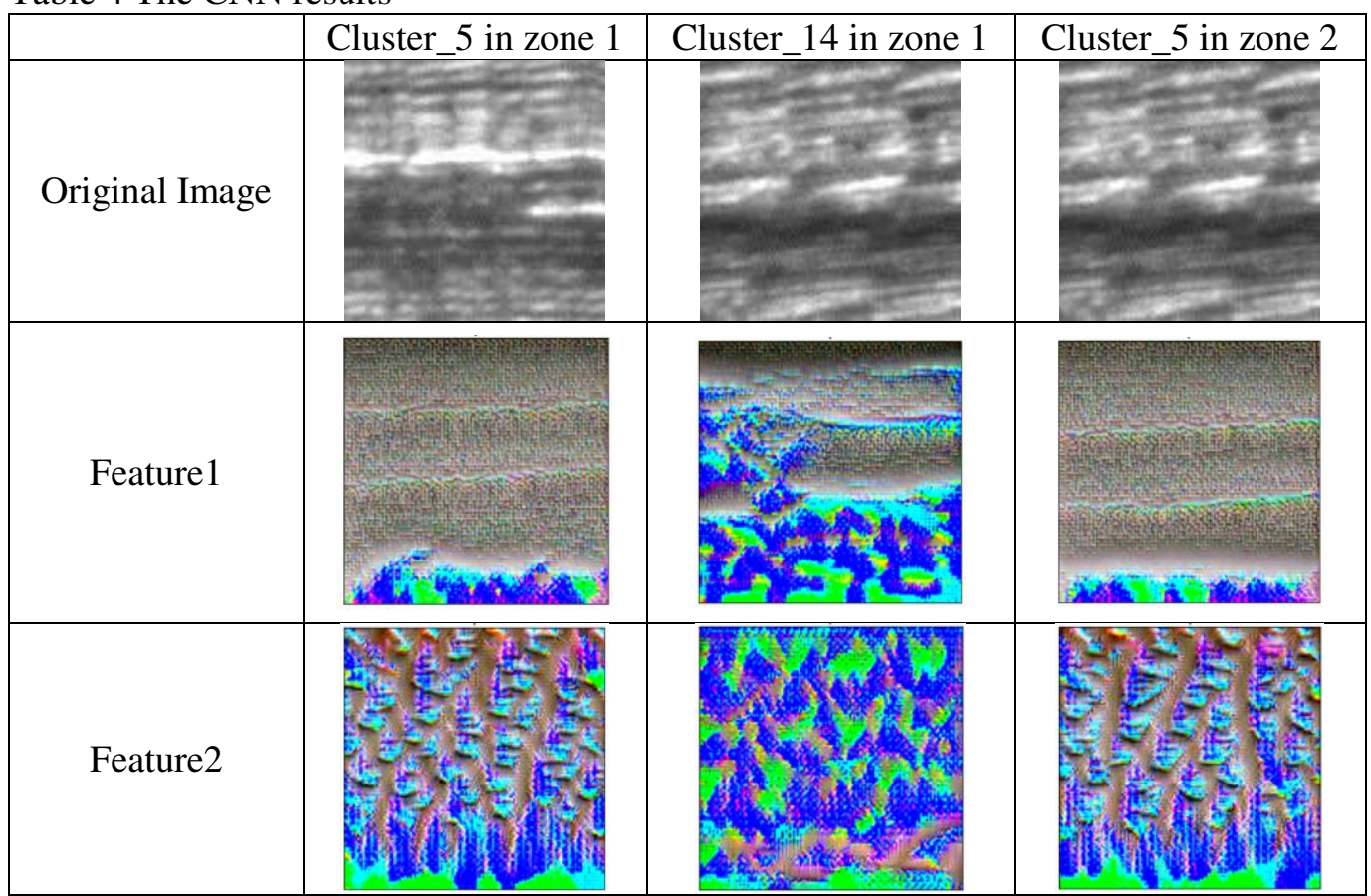

Combining the results of CNN and SVM, which show machining characteristics will leave typifying marks on surfaces, texture features could be identified through surface results after machining with each jerk cluster. Using the six textural features in this study was sufficient to demonstrate classification ability.

\section{(a) Image texture prediction model}

In this study, based on typical industrial practices, a commercial controller was used, and one parameter group setting for the five axes together during the machining of each mold was adopted. 14 geometrically identical blade molds were manufactured with 14 jerk setting clusters (Table 2) and subjected to inspection. From research [7], it is known that the path length affects machining performance. Without loss of generality, the mold was separated into four zones (Fig. 4(a)) with varying curvature contours and path lengths (Table 3), which were to be considered as input parameters. Therefore the input parameters for the workpiece manufacture included jerk values of each axis, the average path length of each zone, cutting tool feed rate, and spindle rotation speed of tool. The output parameters were the six image textures from image processing. Some examples of surface images are shown in Fig. 9. 


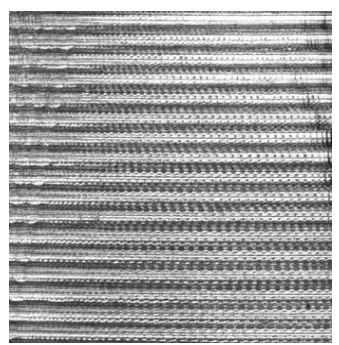

(a) Original surface image

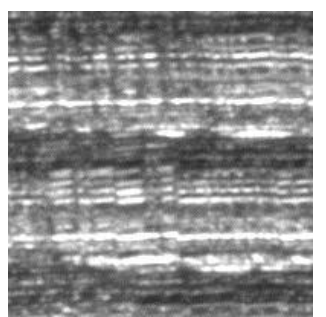

(b) Training data image-1

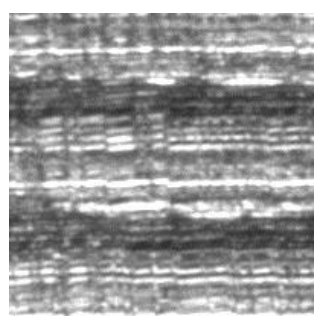

(c) Training data images-2

Fig. 9 Some examples of machining surface image

The parameters and architecture of the model are shown in Fig. 10. A total of 2016 surface image samples from 14 molds were used as training data and 504 samples used as a validation test. Each jerk setting cluster had 45 samples. The results of the validation test are shown in Table 5.

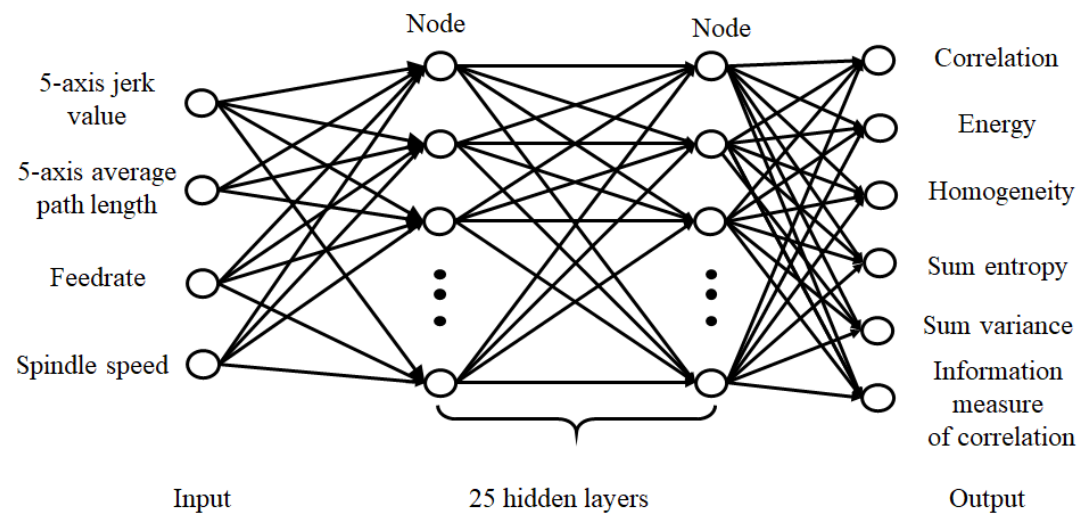

Fig.10 The image texture prediction model structure

Table 5 The image texture prediction model results

\begin{tabular}{|c|c|}
\hline Output result & Predict error (\%) \\
\hline Correlation & 0.317 \\
\hline Energy & 0.839 \\
\hline Homogeneity & 0.367 \\
\hline Sum entropy & 2.698 \\
\hline Sum variance & 2.063 \\
\hline Information measure of correlation & 0.400 \\
\hline
\end{tabular}

\section{(b) Roughness prediction model}

To get the final roughness values, the six features from the GLCM were used as inputs. 2016 samples were used as training data and 504 samples were used in validation. The parameters and neural net architecture are shown in Fig. 11, while Table 6 summarizes the measured and predicted values of Zone 1-4. The average prediction error is only $0.272 \%$. 


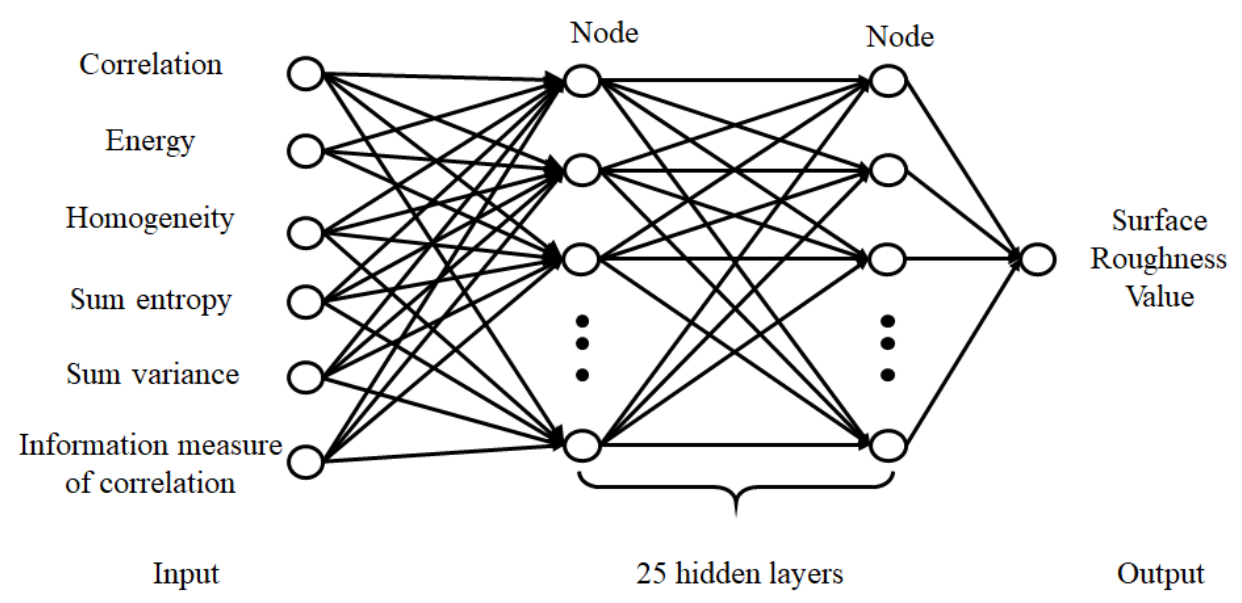

Fig. 11 The roughness prediction model structure

Table 6 The roughness measured/predicted values

\begin{tabular}{|r|r|r|r|r|r|r|r|r|}
\hline \multirow{2}{*}{ Item } & \multicolumn{2}{|c|}{ Zone 1 } & \multicolumn{2}{c|}{ Zone 2 } & \multicolumn{2}{c|}{ Zone 3 } & \multicolumn{2}{c|}{ Zone 4 } \\
\cline { 2 - 10 } Group & Predicted & Measured & Predicted & Measured & Predicted & Measured & Predicted & Measured \\
\hline 1 & 2.230 & 2.230 & 2.749 & 2.750 & 2.367 & 2.370 & 2.141 & 2.130 \\
\hline 2 & 2.090 & 2.090 & 2.268 & 2.265 & 2.127 & 2.110 & 2.273 & 2.270 \\
\hline 3 & 2.282 & 2.280 & 2.167 & 2.165 & 2.270 & 2.270 & 2.249 & 2.250 \\
\hline 4 & 2.334 & 2.333 & 2.500 & 2.498 & 2.394 & 2.393 & 2.358 & 2.360 \\
\hline 5 & 2.252 & 2.250 & 2.110 & 2.110 & 2.212 & 2.210 & 2.285 & 2.290 \\
\hline 6 & 2.330 & 2.330 & 2.231 & 2.230 & 2.190 & 2.190 & 2.243 & 2.230 \\
\hline 7 & 2.328 & 2.330 & 2.390 & 2.390 & 2.170 & 2.170 & 2.198 & 2.220 \\
\hline 8 & 2.423 & 2.423 & 2.529 & 2.525 & 2.380 & 2.380 & 2.417 & 2.420 \\
\hline 9 & 2.181 & 2.180 & 2.138 & 2.137 & 2.195 & 2.193 & 2.242 & 2.246 \\
\hline 10 & 2.244 & 2.245 & 2.254 & 2.250 & 2.263 & 2.220 & 2.147 & 2.150 \\
\hline 11 & 2.295 & 2.295 & 2.105 & 2.080 & 2.171 & 2.170 & 2.241 & 2.180 \\
\hline 12 & 2.279 & 2.280 & 2.251 & 2.250 & 2.351 & 2.350 & 2.219 & 2.190 \\
\hline 13 & 2.317 & 2.317 & 2.302 & 2.315 & 2.254 & 2.255 & 2.279 & 2.313 \\
\hline 14 & 2.398 & 2.399 & 2.440 & 2.445 & 2.357 & 2.357 & 2.352 & 2.353 \\
\hline
\end{tabular}

(c) Machining time estimation model

For the machining time estimate, the model used the total tool path length instead of the separate path length in each zone. The total path length data could be calculated from CAM. Additionally, the output was the single metric of machining time. The parameters and neural net architecture are shown in Fig. 12. The actual and estimated machining times are shown in Table 7 and there was an average error of $-0.472 \%$. 


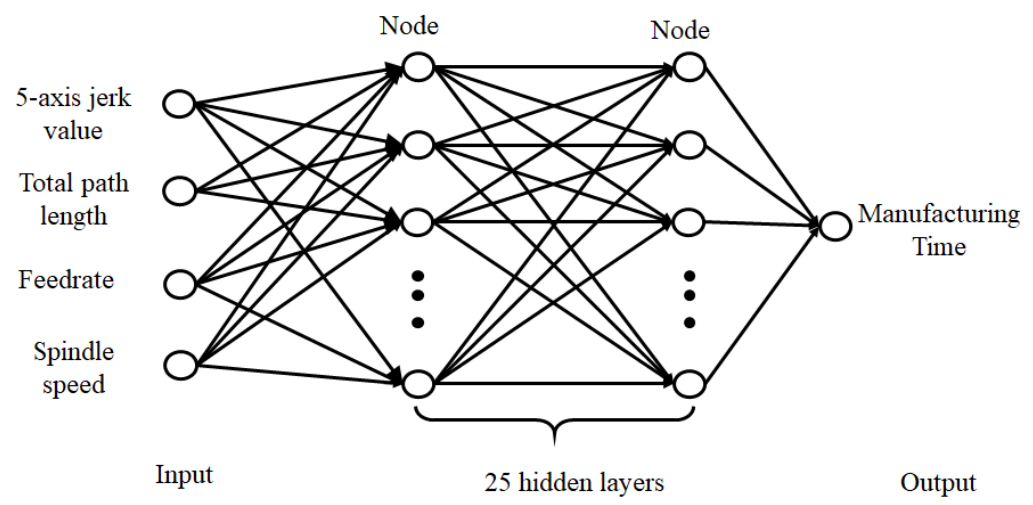

Fig. 12 The machining time estimation model structure

Table 7 Machining time estimated model result

\begin{tabular}{|c|c|c|c|}
\hline Cluster No. & Predicted time (s) & Measured time (s) & Error (\%) \\
\hline 1 & 1656.8 & 1663 & -0.37 \\
\hline 2 & 1637.6 & 1658 & -1.23 \\
\hline 3 & 1728.5 & 1641 & 5.33 \\
\hline 4 & 1386.3 & 1402 & -1.12 \\
\hline 5 & 1405.1 & 1414 & -0.63 \\
\hline 6 & 1965.5 & 1969 & -0.18 \\
\hline 7 & 1570.2 & 1577 & -0.43 \\
\hline 8 & 1689.8 & 1687 & 0.17 \\
\hline 9 & 1096.6 & 1103 & -0.58 \\
\hline 10 & 1610.3 & 1630 & -1.21 \\
\hline 11 & 1376.9 & 1381 & -0.30 \\
\hline 12 & 1719.9 & 1820 & -5.50 \\
\hline 13 & 1130.7 & 1136 & -0.46 \\
\hline 14 & 1098.8 & 1100 & -0.11 \\
\hline
\end{tabular}

\subsection{Summary and discussions}

The results of this experiment show:

1. The cutting mechanism leaves tool marks (scallops and cusps), and the resulting surface texture of the workpiece is a faithful representation of the parameter changes of the machining process, typically the effect of changes to jerk setting values. The SVM and CNN results show the six selected texture features are significant characteristics of the image.

2. The training data included four different curvature zones, simulating a typical workpiece that includes various contour surfaces. The system was able to predict the 
surface roughness for 14 groups of jerk settings in all zones. The image texture characteristics of the workpiece surface could be predicted from the input that included the information about the workpiece, dynamic parameters of the machine, and cutting conditions. Surface roughness could be estimated from the texture characteristics of the workpiece surface. Also, the processing time required could be estimated from the input processing conditions. The final average estimated performances produced only $0.272 \%$ and $-0.472 \%$ error rates for roughness and machining time, respectively.

3. To summarize the achievements of this study, an integrated system for manufacturing performance prediction is available, as shown in Fig 10. A real highspeed 5-axis machining system (in Fig 2) can be replaced with a virtual machine tool module. We have successfully demonstrated the integrated prediction system with the input: workpiece information, cutting parameters and machine tool parameters, as an experiment. And the output: predicted roughness, compared with the measured data shows only minimal error (in Table 8). The predicted machining time and the actual values were only minimally different (see Table 7). A separate branch of the system, the roughness prediction module combined with surface texture processor, can be used as an independent module for surface quality inspection when surface images of a workpiece are available.

4. Additionally, it can be observed from the $\mathrm{CNN}$ feature map analysis that different jerk value settings can produce different higher-level patterns deeper in the network. As seen in the pictures in Table 4, the same area of concern will exhibit different features with different jerk settings, showing that jerk does indeed give rise to different textural features. Equivalent jerk settings will produce similar feature images, proving again that jerk is an important parameter that affects surface texture during synchronous machining. The results of this study and comparisons with other research on surface roughness prediction systems are listed in Table 9.

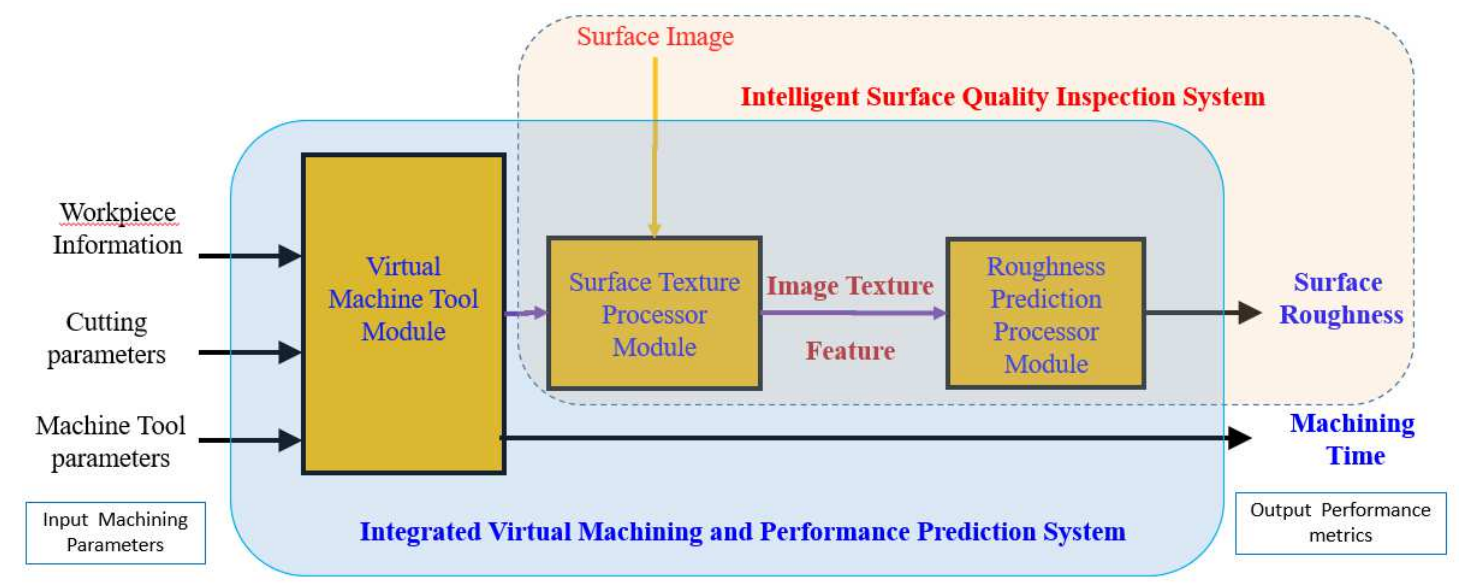

Fig. 10 Integrated Performance Prediction System Diagram

Table 8 Roughness value predicted/measured results

\begin{tabular}{|c|c|c|c|}
\hline Cluster No & Predicted $(\mu \mathrm{m})$ & Measured $(\mu \mathrm{m})$ & Error $(\%)$ \\
\hline 1 & 2.339 & 2.370 & -1.317 \\
\hline 2 & 2.336 & 2.184 & 6.965 \\
\hline
\end{tabular}




\begin{tabular}{|c|c|c|c|}
\hline 3 & 2.317 & 2.241 & 3.376 \\
\hline 4 & 2.538 & 2.396 & 5.914 \\
\hline 5 & 2.305 & 2.215 & 4.071 \\
\hline 6 & 2.529 & 2.245 & 12.661 \\
\hline 7 & 2.351 & 2.278 & 3.227 \\
\hline 8 & 2.328 & 2.437 & -4.481 \\
\hline 9 & 2.330 & 2.189 & 6.432 \\
\hline 10 & 2.365 & 2.216 & 6.695 \\
\hline 11 & 2.335 & 2.181 & 7.035 \\
\hline 12 & 2.303 & 2.268 & 1.547 \\
\hline 13 & 2.222 & 2.300 & -3.383 \\
\hline 14 & 2.273 & 2.389 & -4.828 \\
\hline
\end{tabular}

Table 9 Comparison with the results of other surface roughness prediction systems

\begin{tabular}{|c|c|c|c|c|}
\hline Researcher & $\begin{array}{l}\text { Manufacturing } \\
\text { (Material) }\end{array}$ & $\begin{array}{l}\text { Predictive model } \\
\text { architecture }\end{array}$ & Input parameters & $\begin{array}{l}\text { Prediction } \\
\text { error }\end{array}$ \\
\hline Xie[41], 2018 & Turning & $\mathrm{SVM}+\mathrm{PSO}$ & $\begin{array}{l}\text { Spindle speed, Cutting depth, } \\
\text { Feedrate, Cutting energy }\end{array}$ & $4.86 \%$ \\
\hline $\begin{array}{l}\text { Sekulic[42], } \\
2018\end{array}$ & $\begin{array}{l}\text { Plane milling } \\
\text { (hardened steel } \\
\text { X210CR12) }\end{array}$ & $\begin{array}{c}\text { Grey Wolf } \\
\text { Optimizer (GWO) } \\
\text { model }\end{array}$ & $\begin{array}{l}\text { Spindle speed, Feed per tooth, } \\
\text { Axial depth, Depth of cut }\end{array}$ & $10.42 \%$ \\
\hline $\begin{array}{l}\text { Kayabaşi[33] } \\
2019\end{array}$ & $\begin{array}{l}\text { Plane milling, } \\
\text { (Aluminum } \\
\text { alloy) }\end{array}$ & Probabilistic model & 3-axis (XYZ) vibration signal & $3.63 \%$ \\
\hline $\begin{array}{l}\text { Ngerntong[43] } \\
2020\end{array}$ & $\begin{array}{l}\text { Face milling } \\
\text { (Aluminum } \\
\text { 7075-T6) }\end{array}$ & Fuzzy control & $\begin{array}{l}\text { Chip continuity, Chip } \\
\text { deformation, Chip thickness }\end{array}$ & $6.55 \%$ \\
\hline $\begin{array}{l}\text { Marani[44], } \\
2020\end{array}$ & $\begin{array}{l}\text { Plane milling } \\
\text { (Al-20 Mg2Si } \\
\text { metal matrix } \\
\text { composite) }\end{array}$ & $\begin{array}{l}\text { Adaptive network- } \\
\text { based fuzzy inference } \\
\text { systems (ANFISs) }\end{array}$ & $\begin{array}{c}\text { Feed speed, Cutting speed, } \\
\text { Particle size }\end{array}$ & $7.01 \%$ \\
\hline $\begin{array}{l}\text { Beemaraj[45], } \\
2020\end{array}$ & $\begin{array}{c}\text { Turning } \\
\text { (Aluminum } \\
6063 \text { ) }\end{array}$ & ANFIS & $\begin{array}{l}\text { Skewness, kurtosis, Mean, } \\
\text { Variance, Contrast, Energy }\end{array}$ & $9.71 \%$ \\
\hline Patel[46], 2020 & $\begin{array}{l}\text { Turning } \\
\text { (low carbon } \\
\text { steels) }\end{array}$ & $\begin{array}{l}\text { Linear regression } \\
\text { analysis }\end{array}$ & $\begin{array}{l}\text { Dissimilarity, Energy Entropy, } \\
\text { Homogeneity, Maximum } \\
\text { probability, Sum entropy, } \\
\text { Difference varianc, Difference } \\
\text { entropy, Inverse difference } \\
\text { normalized }\end{array}$ & $0.358 \%$ \\
\hline
\end{tabular}




\begin{tabular}{|c|c|c|c|c|}
\hline $\begin{array}{c}\text { This research- } \\
\text { Image } \\
\text { prediction } \\
\text { module }\end{array}$ & $\begin{array}{c}\text { Free-form } \\
\text { milling } \\
\text { (Aluminum } \\
6061)\end{array}$ & SVM+ANN & $\begin{array}{c}\text { Correlation, Energy, } \\
\text { Homogeneity, Sum entropy, } \\
\text { Sum variance, Information } \\
\text { measure of correlation }\end{array}$ & $0.272 \%$ \\
\hline $\begin{array}{c}\text { This research- } \\
\text { Integrated } \\
\text { forecasting } \\
\text { module }\end{array}$ & $\begin{array}{c}\text { Free-form } \\
\text { milling } \\
\text { (Aluminum } \\
6061)\end{array}$ & ANN & $\begin{array}{c}\text { Axis jerk, axes path length, feed } \\
\text { speed, spindle speed }\end{array}$ & $0.730 \%$ \\
\hline
\end{tabular}

\section{Conclusion}

Surface images of scallops and cusps observed on 14 workpieces caused by different jerk settings in 5-axis synchronization machining have been captured and studied. Image processing technology and machine learning are used to evaluate manufacturing performance (roughness and machining time).

An integrated system, constituting a virtual machine tool module, image processing module and roughness prediction module, has been developed. This system has demonstrated good pre-assessment and quality inspection ability. It gives users the ability to choose the best parameter settings, and to estimate processing time and the quality of the surface before real machining. It also can help users balance the requirement for fast processing times and the need for surface quality in industrial applications.

Authors' contributions: Conceptualization, CFJ Kuo; methodology, CFJ. Kuo and WH. Weng; validation, CFJ. Kuo and WH. Weng; formal analysis, CFJ. Kuo and WH. Weng; data interpretation, CFJ. Kuo and WH. Weng; writing-original draft preparation, WH. Weng; writing - review and editing, CFJ. Kuo; visualization, CFJ. Kuo and WH. Weng; funding acquisition, CFJ. Kuo.

All authors have read and agreed to the published version of the manuscript.

Funding: The research was supported by the Ministry of Science and Technology of the Republic of China under Grant No. 109-2221-E-011 -149.

Data availability All data sets generated in this study are available from the corresponding author upon reasonable request.

Compliance with ethical standards

Competing interests The authors declare that they have no competing interests.

Ethical approval Not applicable.

Consent to participate Not applicable.

Consent to publish Not applicable.

\section{Reference}

[1] Jia ZY, Ma JW, Song DN, Wang FJ, Liu W (2018) A review of contouring-error reduction method in multi-axis CNC machining. Int J Mach Tools Manuf 125:3454. https://doi.org/10.1016/j.ijmachtools.2017.10.008

[2] Lai ZH, Tao W, Leu MC, Yin Z (2020) Smart augmented reality instructional system for mechanical assembly towards worker-centered intelligent $\begin{array}{llll}\text { manufacturing. } & \mathrm{J} & \text { Manuf } & \text { Syst }\end{array}$ https://doi.org/10.1016/j.jmsy.2020.02.010

[3] Ansoategui I, Campa FJ, López C, Díez M (2017) Influence of the machine tool 
compliance on the dynamic performance of the servo drives. Int J Adv Manuf Technol 90:2849-2861. https://doi.org/10.1007/s00170-016-9616-y

[4] Duong TQ, Rodriguez-Ayerbe P, Lavernhe S, Tournier C, Dumur D (2018) Contour error pre-compensation for five-axis high speed machining: offline gain adjustment approach. Int $\mathbf{J}$ Adv Manuf Technol 100:3113-3125. https://doi.org/10.1007/s00170-018-2859-z

[5] Tsai MS, Huang YC (2016) A novel integrated dynamic acceleration/deceleration interpolation algorithm for a CNC controller. Int J Adv Manuf Technol 87:-292. https://doi.org/10.1007/s00170-016-8444-4

[6] Chu $\mathrm{CH}$, Chen $\mathrm{HY}$, Chang $\mathrm{CH}$ (2020) Continuity-preserving tool path generation for minimizing machining errors in five-axis CNC flank milling of ruled surfaces. J Manuf Syst 55:171-178. https://doi.org/10.1016/j.jmsy.2020.03.004

[7] Weng WH, Kuo CFJ (2019) Jerk decision for free-form surface effects in multiaxis synchronization manufacturing. Int $\mathbf{J}$ Adv Manuf Technol. 105:799-812 https://doi.org/10.1007/s00170-019-04164-5

[8] Castagnetti C, Duc E, Ray P (2008) The Domain of Admissible Orientation concept: A new method for five-axis tool path optimization. Comput Aided Des 40:938-950. https://doi.org/10.1016/j.cad.2008.07.002

[9] Han J, Jiang Y, Tian X, Chen F, Lu C, Xia L (2018) A local smoothing interpolation method for short line segments to realize continuous motion of tool axis acceleration. Int $J$ Adv Manuf Technol 95:1729-1742. https://doi.org/10.1007/s00170-017-1264-3

[10] Erkorkmaz K, Altintas Y (2001) High speed CNC system design. Part I: jerk limited trajectory generation and quintic spline interpolation. Int $\mathrm{J}$ Mach Tools Manuf 41:1323-1345. https://doi.org/10.1016/S0890-6955(01)00002-5

[11] Beudaert X, Pechard PY, Tournier C (2011) 5-Axis tool path smoothing based on drive constraints. Int $J$ Mach Tools Manuf 51:958-965. https://doi.org/10.1016/j.ijmachtools.2011.08.014

[12] Barre PJ, Bearee R, Borne P, Dumetz E (2005) Influence of a jerk controlled movement law on the vibratory behaviour of high-dynamics systems. J. Intell. Manuf. 42:275-293. https://doi.org/10.1007/s10846-004-4002-7

[13] Zhang Y, Ye P, Wu J, Zhang H (2018) An optimal curvature-smooth transition algorithm with axis jerk limitations along linear segments. Int J Adv Manuf Technol 95:875-888. https://doi.org/10.1007/s00170-017-1274-1

[14] Tulsyan S, Altintas Y(2015) Local toolpath smoothing for five-axis machine tools. Int. J. Mach. Tools 96:15-26. https://doi.org/10.1016/j.ijmachtools.2015.04.014

[15] Sato Y, Nakanishi T, Sato R, Shirase K, Oda M, Nakayama N (2016) Study on the evaluation method for finished surface based on human visual characteristic. In 2016 International Symposium on Flexible Automation (ISFA) 428-431. 10.1109/ISFA.2016.7790201

[16] Jeyapoovan T, Murugan M (2013) Surface roughness classification using image processing. Meas 46:2065-2072. https://doi.org/10.1016/j.measurement.2013.03.014

[17] Manish R, Venkatesh A, Ashok SD (2018) Machine vision based image processing techniques for surface finish and defect inspection in a grinding process. Mater Today Proc 5:12792-12802. https://doi.org/10.1016/j.matpr.2018.02.263

[18] Lu C (2008) Study on prediction of surface quality in machining process. J Mater Process Technol 205:439-450. https://doi.org/10.1016/j.jmatprotec.2007.11.270 
[19] Wang J, Fu P, Gao RX (2019) Machine vision intelligence for product defect inspection based on deep learning and Hough transform. J Manuf Syst 51:52-60. https://doi.org/10.1016/j.jmsy.2019.03.002

[20] Martínez SS, Vázquez CO, García JG, Ortega JG (2017) Quality inspection of machined metal parts using an image fusion technique. Meas 111:374-383. https://doi.org/10.1016/j.measurement.2017.08.002

[21] Cuka B, Cho M, Kim DW (2018) Vision-based surface roughness evaluation system for end milling. Int $\mathrm{J}$ Comput Integr Manuf 2018:727-738. https://doi.org/10.1080/0951192X.2017.1407451

[22] Joshi KN, Patil BT (2018) A Review of Machine Vision based Evaluation of Surface Roughness using Texture Analysis Techniques. Ind Eng J 11 https://doi.org/10.26488/IEJ.11.11.1150

[23] Wang J, Ma Y, Zhang L, Gao RX, Wu D (2018) Deep learning for smart manufacturing: Methods and applications. J Manuf Syst 48:144-156. https://doi.org/10.1016/j.jmsy.2018.01.003

[24] Ning F, Shi Y, Cai M, Xu W, Zhang X (2020) Manufacturing cost estimation based on the machining process and deep-learning method. J Manuf Syst 56:1122. https://doi.org/10.1016/j.jmsy.2020.04.011

[25] Benardos PG, Vosniakos GC (2003) Predicting surface roughness in machining: a review. Int J Mach Tools Manuf 43(8):833-844. https://doi.org/10.1016/S08906955(03)00059-2

[26] Zhu Z, Brilakis I (2010) Machine vision-based concrete surface quality assessment. J Constr Eng Manag 136:210-218. https://doi.org/10.1061/(ASCE)CO.1943-7862.0000126

[27] Asiltürk I, Çunkaş M (2011) Modeling and prediction of surface roughness in turning operations using artificial neural network and multiple regression method. Expert Syst Appl 38:5826-5832. https://doi.org/10.1016/j.eswa.2010.11.041

[28] Patel DR, Vakharia V, Kiran MB (2019) Texture classification of machined surfaces using image processing and machine learning techniques. FME Trans 47:865-872. https://doi.org/10.5937/fmet1904865P

[29] Morala-Argüello P, Barreiro J, Alegre E (2012) A evaluation of surface roughness classes by computer vision using wavelet transform in the frequency domain. Int J Adv Manuf Technol 59(1-4):213-220. https://doi.org/10.1007/s00170-011$\underline{3480-6}$

[30] Özel T, Karpat Y (2005) Predictive modeling of surface roughness and tool wear in hard turning using regression and neural networks. Int J Mach Tools Manuf 45(4-5): 467-479. https://doi.org/10.1016/j.ijmachtools.2004.09.007

[31] Zain AM, Haron H, Sharif S (2010) Prediction of surface roughness in the end milling machining using Artificial Neural Network. Expert Syst. Appl. 37:17551768. https://doi.org/10.1016/j.eswa.2009.07.033

[32] Ramesh R, Kumar KR, Anil G (2009) Automated intelligent manufacturing system for surface finish control in CNC milling using support vector machines. Int J Adv Manuf Technol 42(11-12):1103-1117 https://doi.org/10.1007/s00170008-1676-1.

[33] Kayabaşi O, Ertürk Ş (2019) On-Line Surface Roughness Prediction by Using a Probabilistic Approach for End-Milling. IEEE Access, 7:143490-143498. 10.1109/ACCESS.2019.2944769

[34] Ansoategui I, Campa FJ, López C, Díez M (2017) Influence of the machine tool compliance on the dynamic performance of the servo drives. Int J Adv Manuf Technol 90:2849-2861. https://doi.org/10.1007/s00170-016-9616-y 


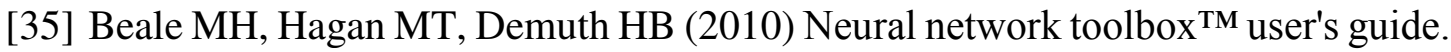
The MathWorks, Natick.

[36] Batista MF, Rodrigues AR, Coelho RT (2017) Modelling and characterisation of roughness of moulds produced by high-speed machining with ball-nose end mill. Proc Inst Mech Eng B J Eng Manuf 231:933-944. https://doi.org/10.1177/0954405415584898

[37] Haralick RM, Shanmugan K, Dinstein IH (1973) Textural features for image classification. IEEE Trans Syst Man Cybern 3:610-621. https://doi.org/10.1109/TSMC.1973.4309314

[38] Soh L, Tsatsoulis C. Texture Analysis of SAR Sea Ice Imagery Using Gray Level Co-Occurrence Matrices. IEEE Trans Geosci Remote Sens 1999;37(2);780-795. https://doi.org/10.1109/36.752194

[39] Rao KV, Murthy PBGSN (2018) Modeling and optimization of tool vibration and surface roughness in boring of steel using RSM, ANN and SVM. J Intell Manuf 29:1533-1543. https://doi.org/10.1007/s10845-016-1197-y

[40] Selvaraju RR, Cogswell M, Das A, Vedantam R, Parikh D, Batra D (2017) Gradcam: Visual explanations from deep networks via gradient-based localization. In 2017 IEEE International Conference on Computer Vision (ICCV) 618-626. 10.1109/ICCV.2017.74

[41] Xie N, Zhou J, Zheng B (2018) An energy-based modeling and prediction approach for surface roughness in turning. Int $\mathrm{J}$ Adv Manuf Technol 96(58):2293-2306. https://doi.org/10.1007/s00170-018-1738-y

[42] Sekulic M, Pejic V, Brezocnik M, Gostimirović M, Hadzistevic M. (2018) Prediction of surface roughness in the ball-end milling process using response surface methodology, genetic algorithms, and grey wolf optimizer algorithm. Adv Prod Eng Manag 13(1):18-30. 10.14743/apem2018.1.270

[43] Ngerntong, S., \& Butdee, S. (2020). Surface roughness prediction with chip morphology using fuzzy logic on milling machine. Mater Today Proceedings https://doi.org/10.1016/j.matpr.2020.02.506

[44] Marani M, Songmene V, Zeinali M, Kouam J, Zedan Y (2020) Neuro-fuzzy predictive model for surface roughness and cutting force of machined Al-20 Mg $2 \mathrm{Si}-2 \mathrm{Cu}$ metal matrix composite using additives. Neural Comput Appl 32(12):8115-8126. https://doi.org/10.1007/s00521-019-04314-6

[45] Beemaraj RK, Chandra SMS, Vijayan V (2020) Computer vision measurement and optimization of surface roughness using soft computing approaches. Trans Inst Meas Control 42(13):2475-2481. https://doi.org/10.1177/0142331220916056

[46] Patel DR, Kiran MB, Vakharia V (2020) Modeling and prediction of surface roughness using multiple regressions: A noncontact approach. Eng Rep 2(2): e12119. https://doi.org/10.1002/eng2.12119 


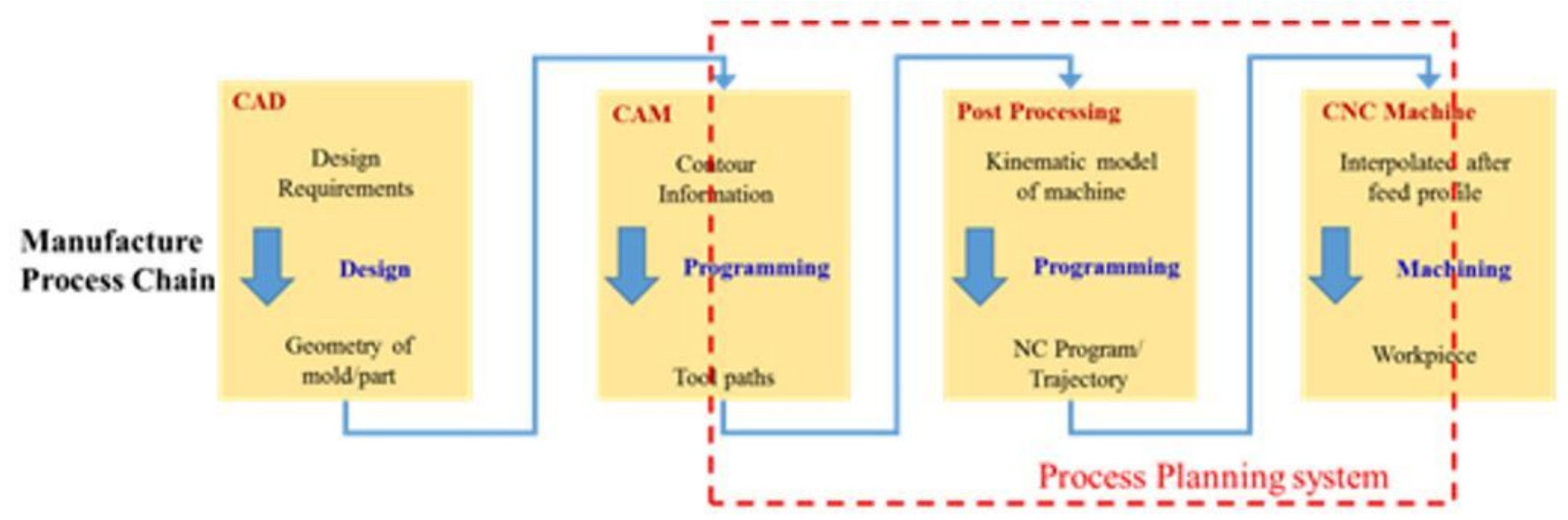

Figure 1

Product development flow and manufacturing process chain diagram [7]
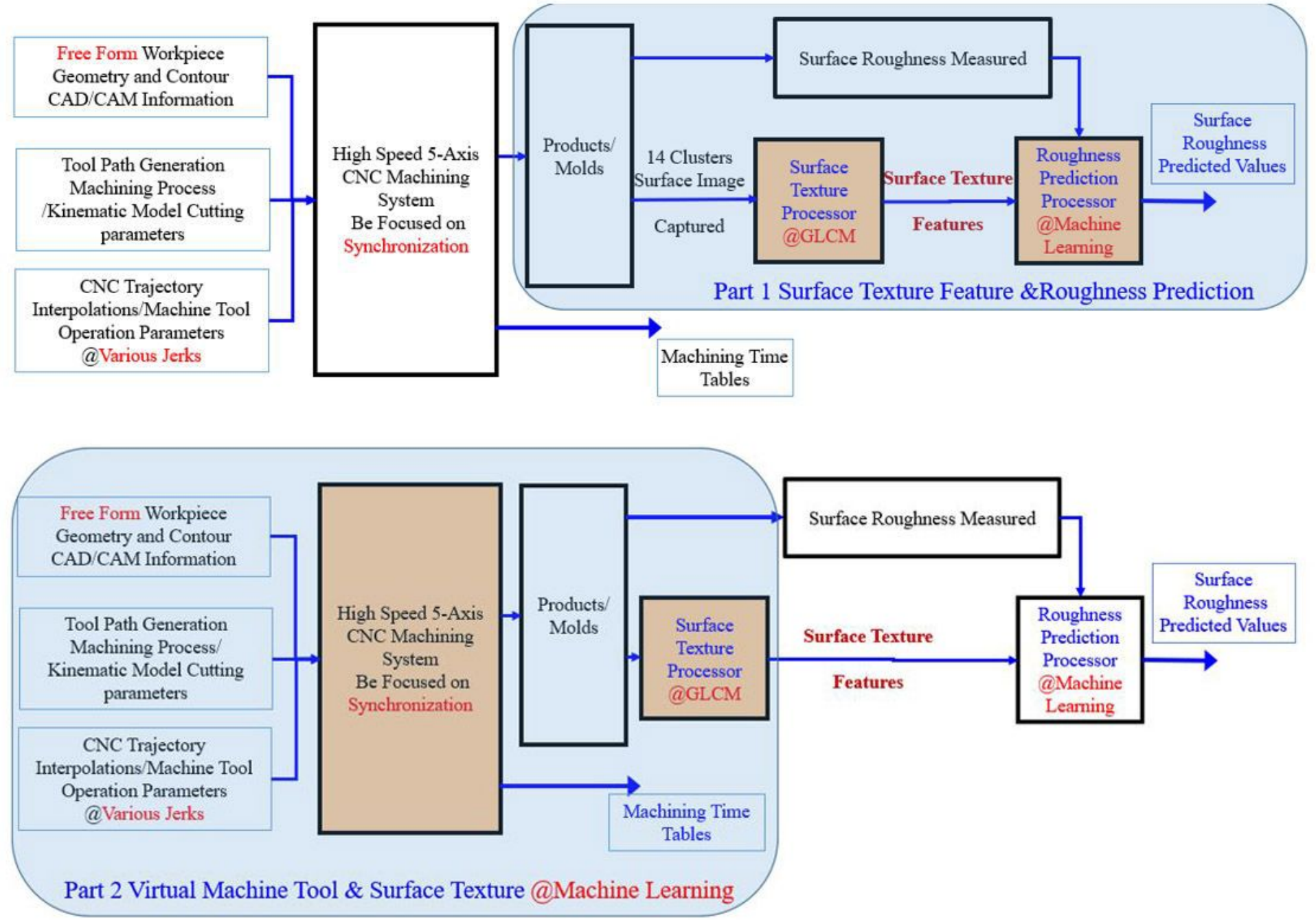
Figure 2

(a) Manufacturing Process Flow Diagram of Part 1. (b) Manufacturing Process Flow Diagram of Part 2. Input Layer of Neurons

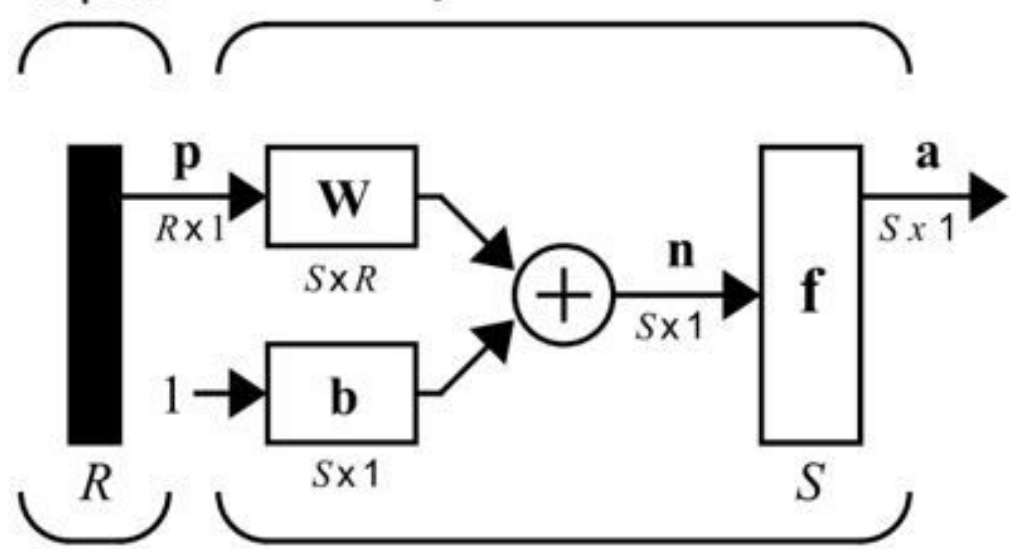

\section{$\mathrm{R}=$ number of elements on vector $\mathrm{S}=$ number of neurons in layer}

Figure 3

A single neuron layer [35]
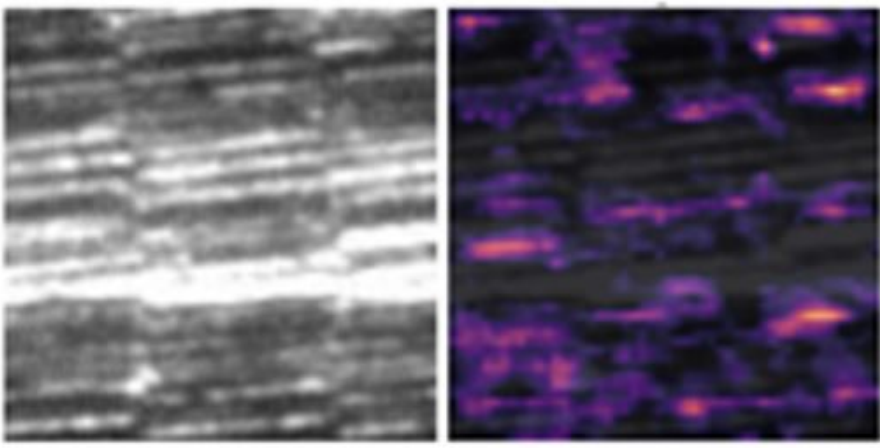

(a) A sample with $2.180 \mu \mathrm{m}$ roughness
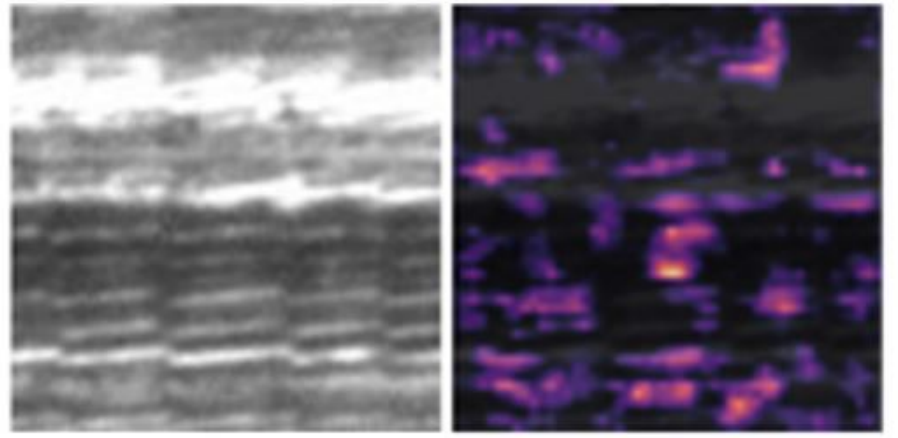

(c) A sample with $2.317 \mu \mathrm{m}$ roughness
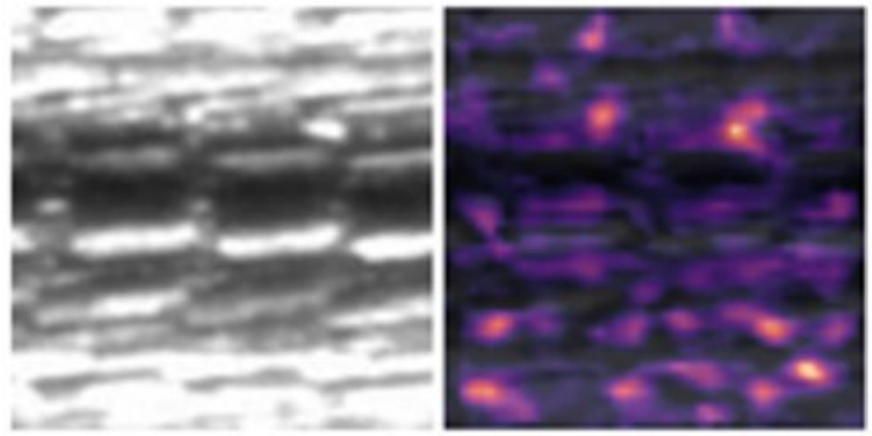

(b) A sample with $2.399 \mu \mathrm{m}$ roughness
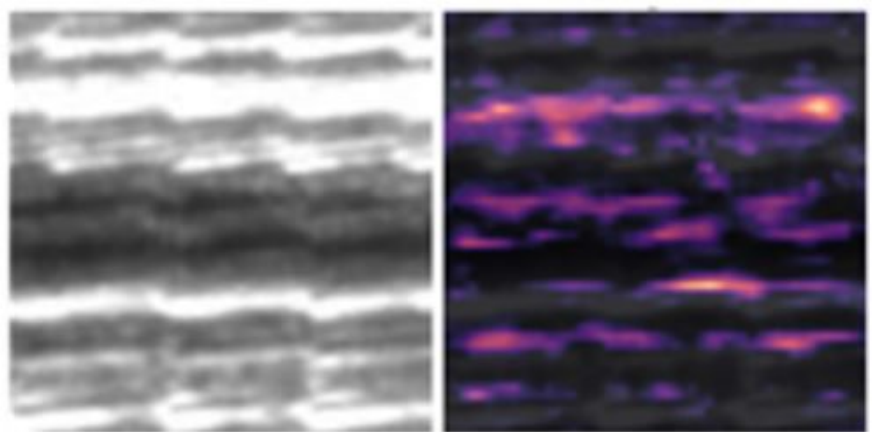

(d) A sample with $2.333 \mu \mathrm{m}$ roughness

Figure 4

Some surface images with heat-map results in zone1 

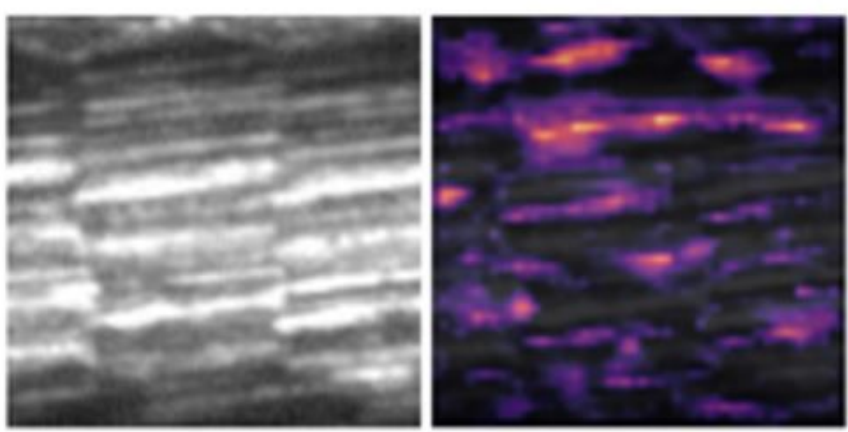

(a) A sample with $2.137 \mu \mathrm{m}$ roughness
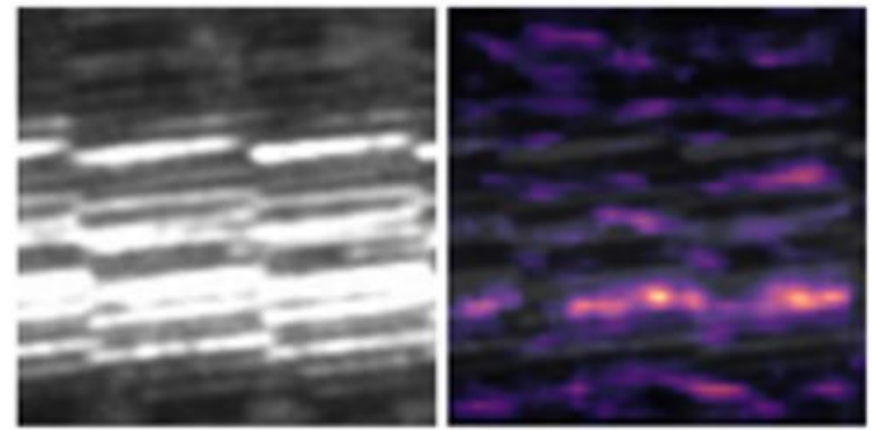

(c) A sample with $2.317 \mu \mathrm{m}$ roughness
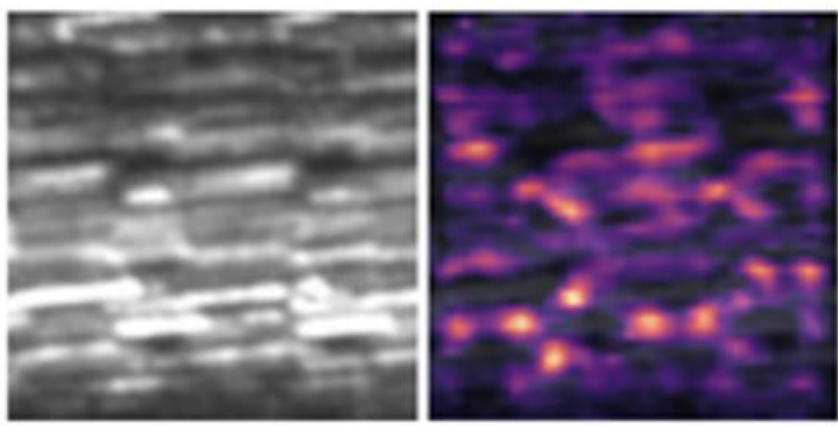

(b) A sample with $2.445 \mu \mathrm{m}$ roughness
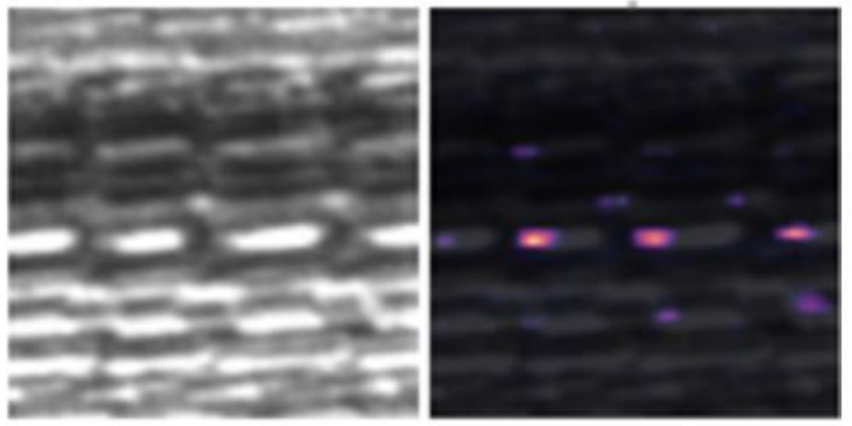

(d) A sample with $2.333 \mu \mathrm{m}$ roughness

\section{Figure 5}

Some surface images with heat-map results in zone2
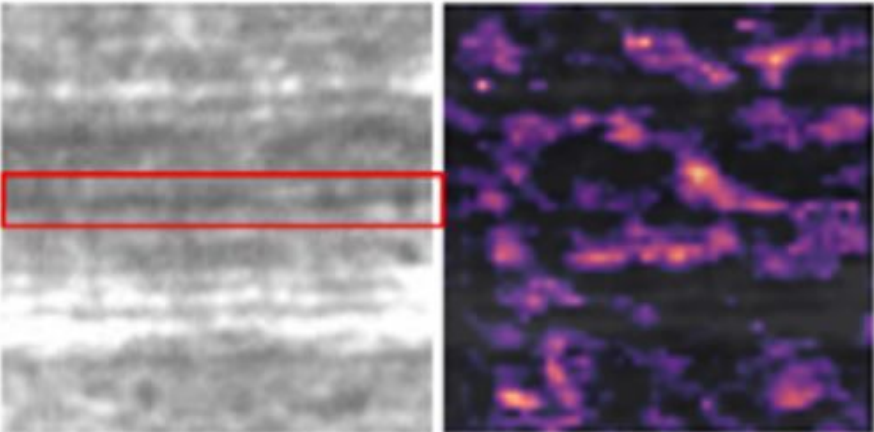

(a) A sample with $2.193 \mu \mathrm{m}$ roughness
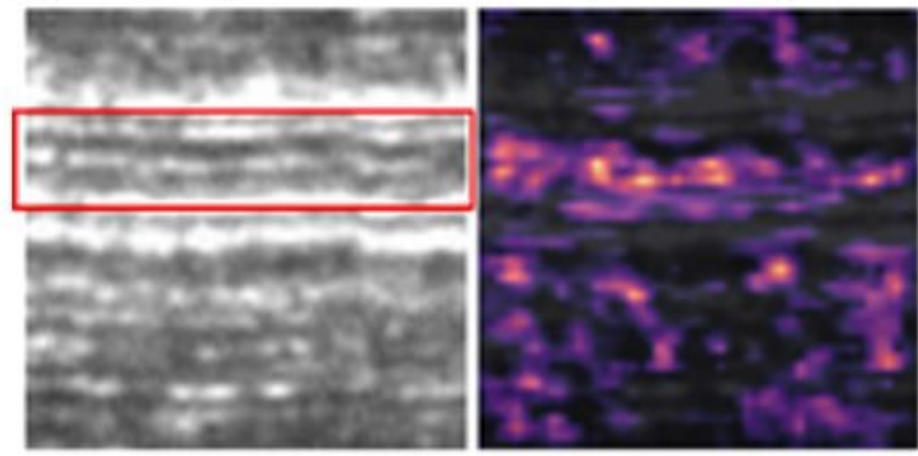

(c) A sample with $2.313 \mu \mathrm{m}$ roughness
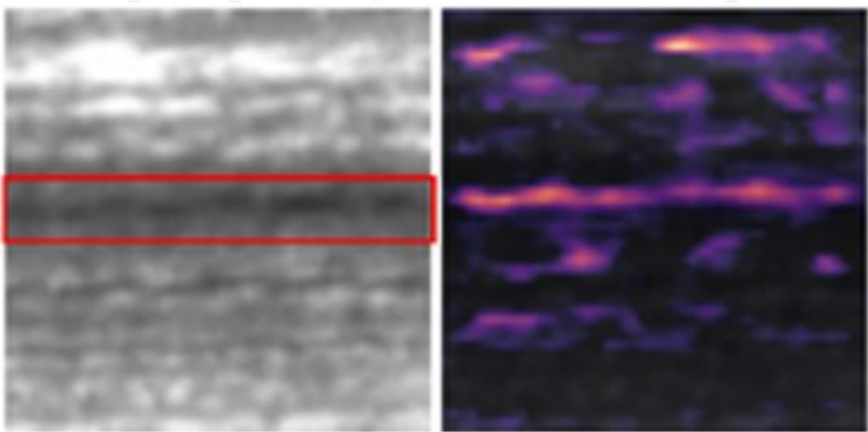

(b) A sample with $2.393 \mu \mathrm{m}$ roughness

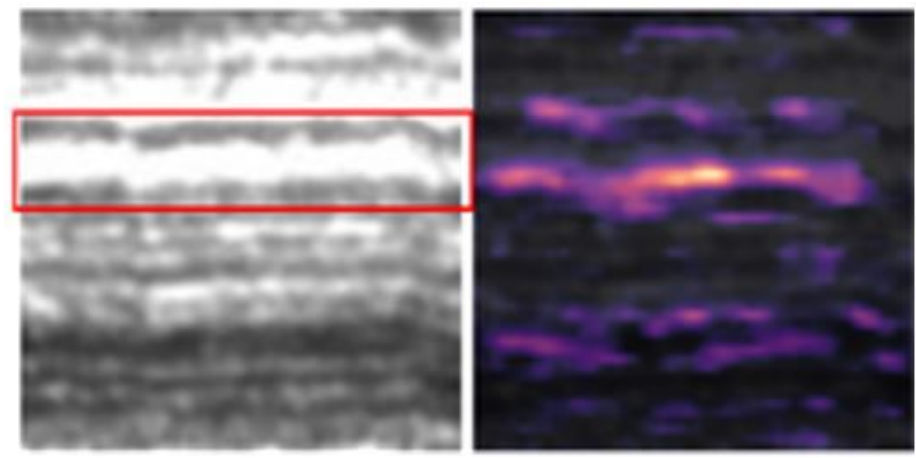

(d) A sample with $2.360 \mu \mathrm{m}$ roughness

Figure 6 
Some surface images with heat-map results in zone3 and zone 4

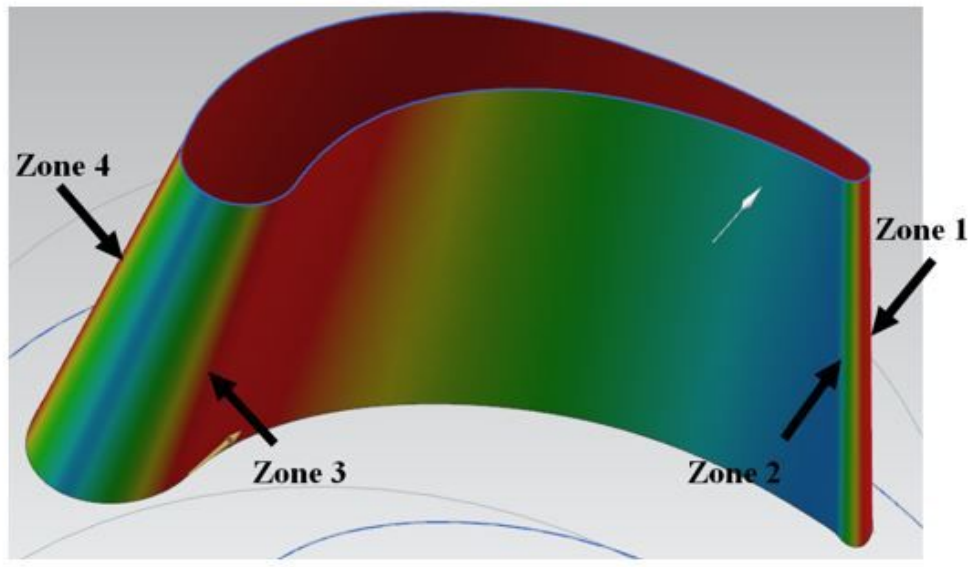

(a) Blade mold, color shows different curvatures

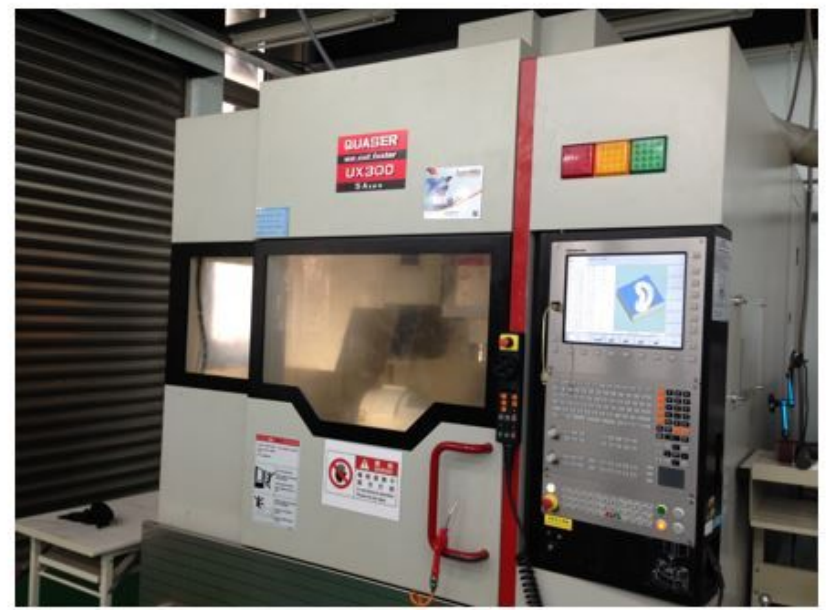

(b) UX-300

Figure 7

The experiment mold and equipment

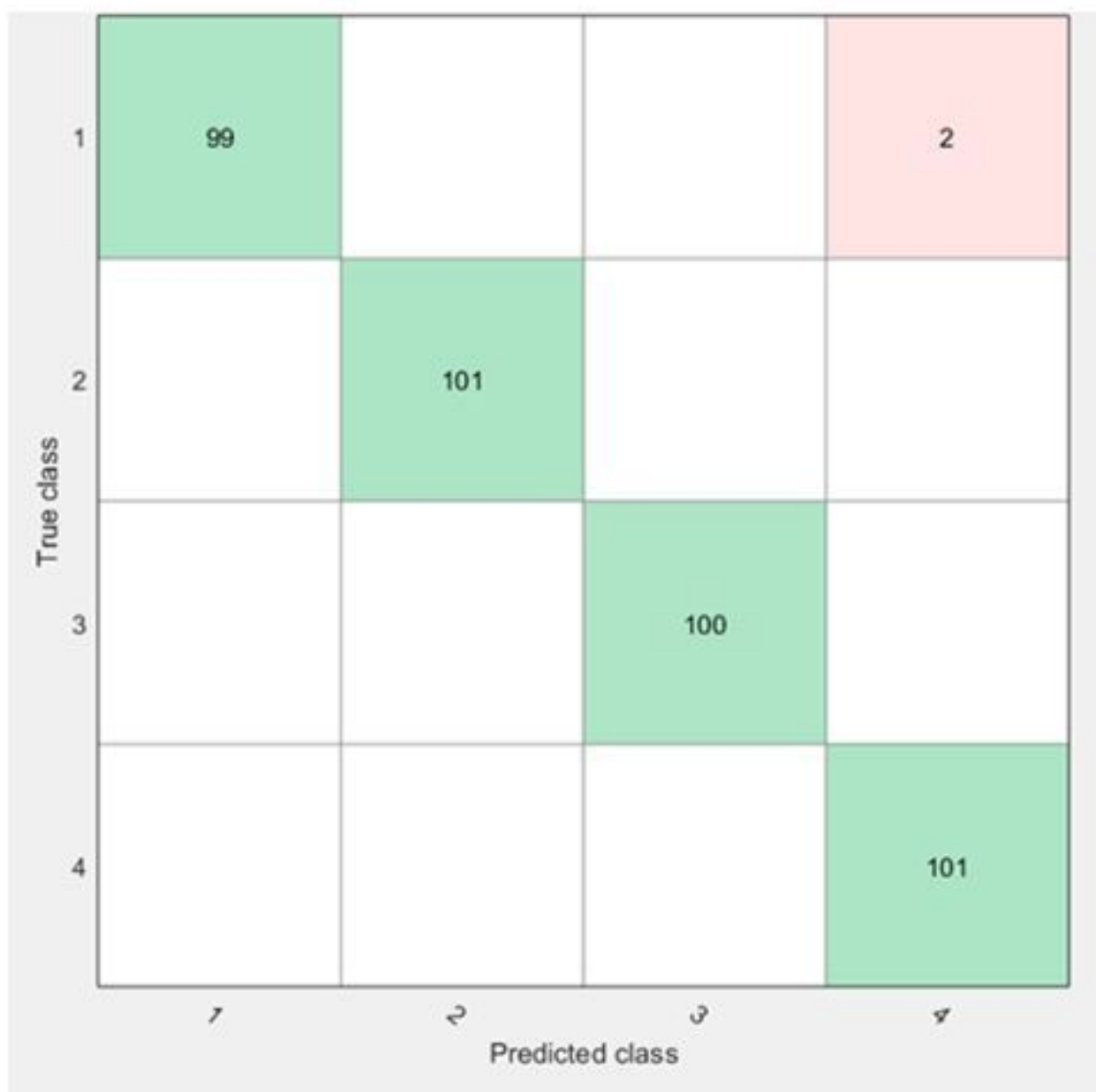

Figure 8

The SVM classified result 


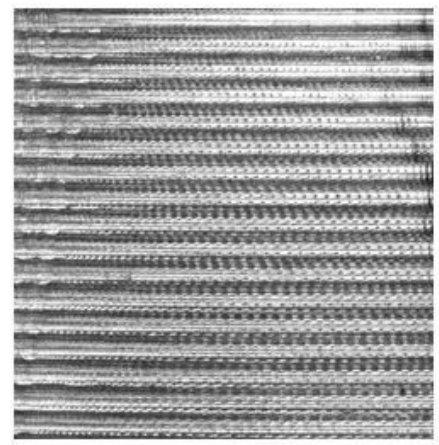

(a) Original surface image

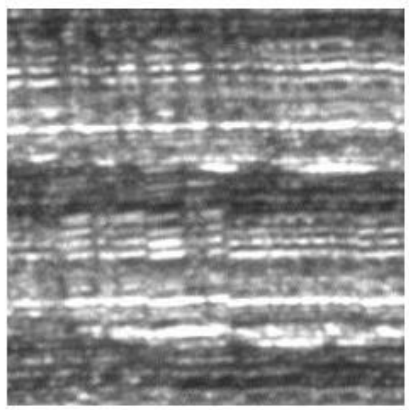

(b) Training data image-1

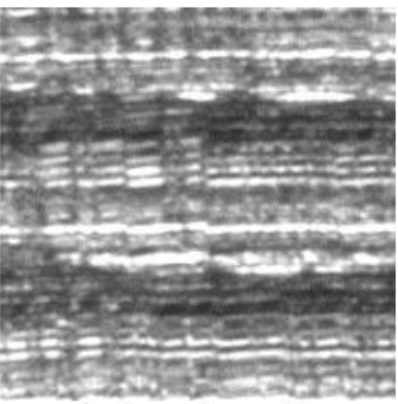

(c) Training data images-2

Figure 9

Some examples of machining surface image

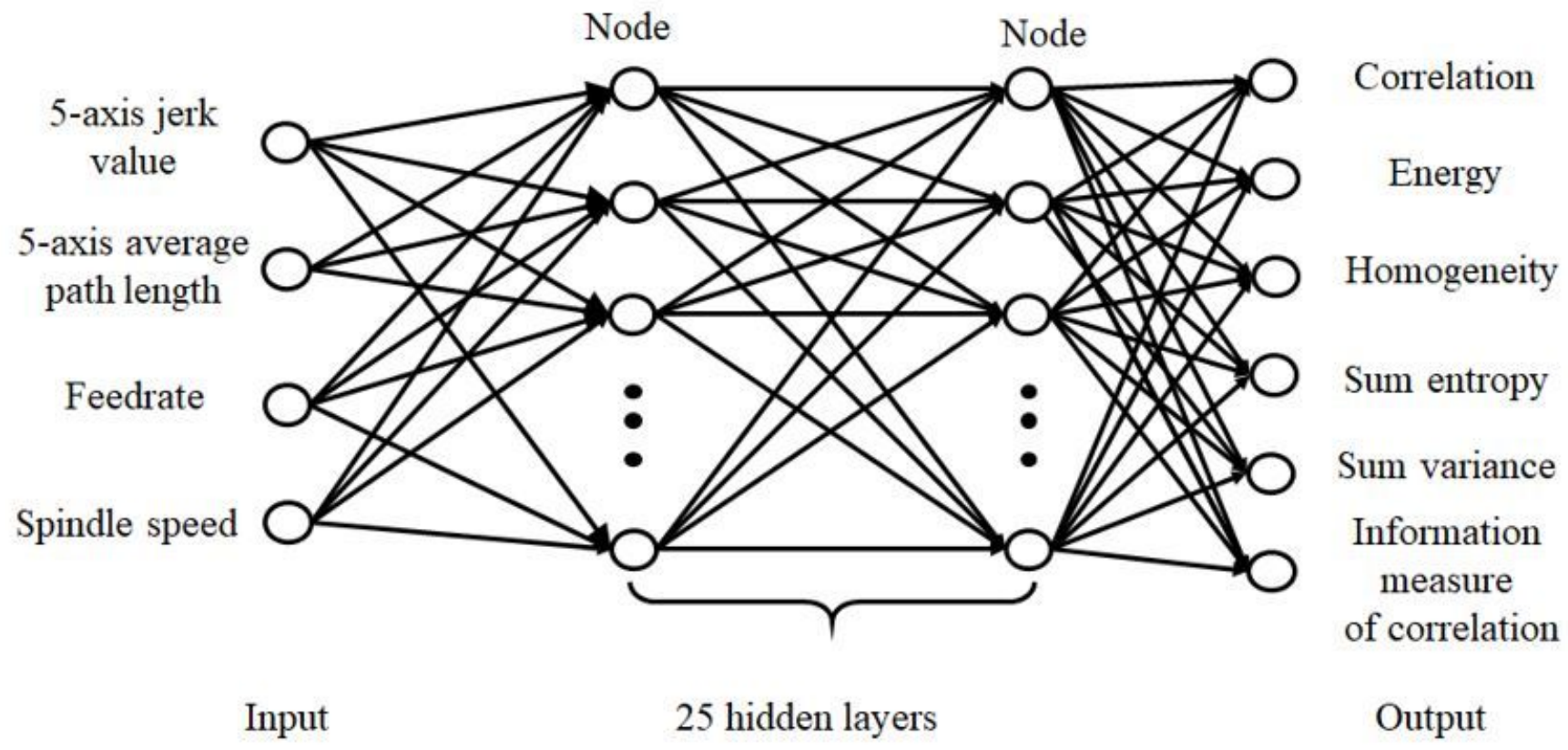

Figure 10

The image texture prediction model structure 


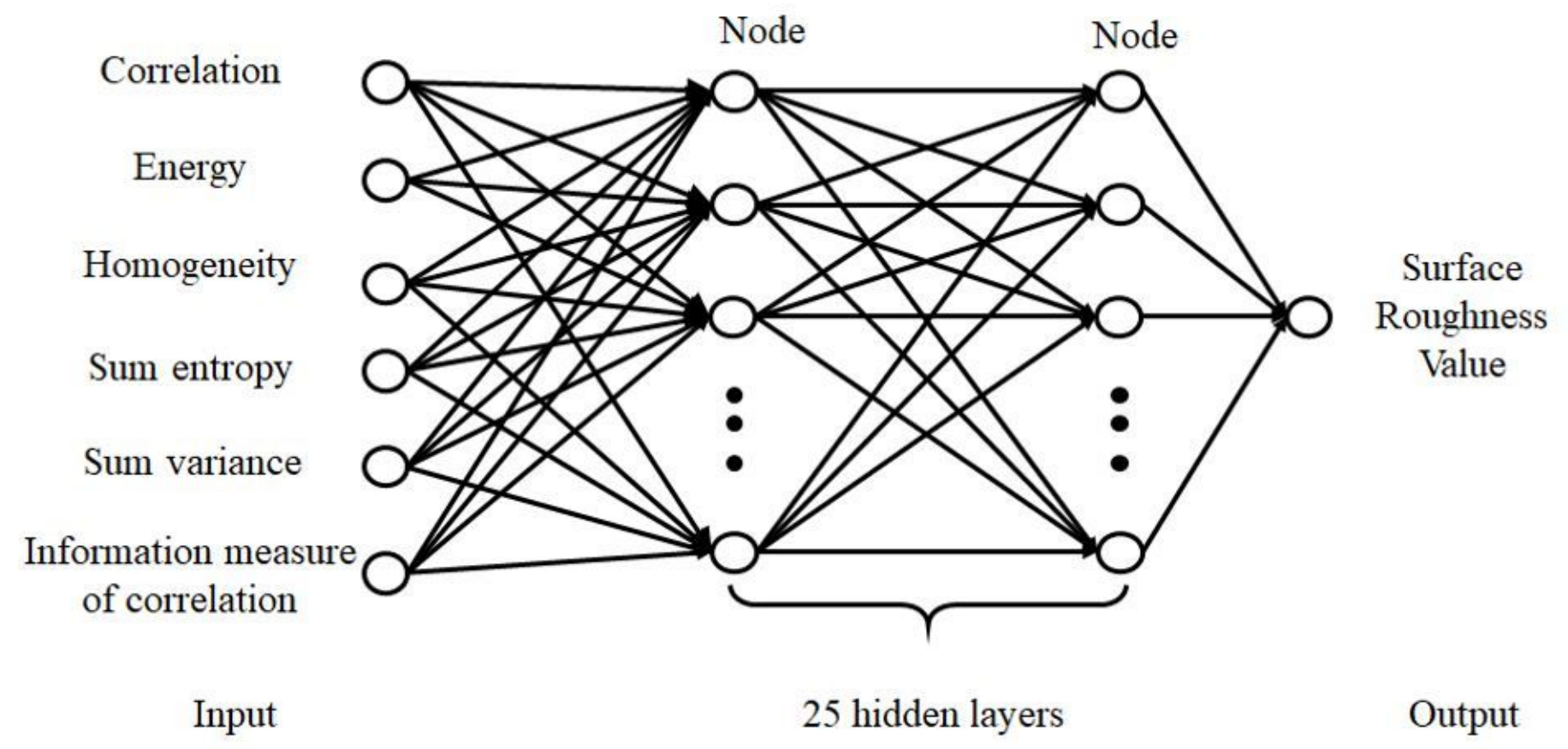

Figure 11

The roughness prediction model structure

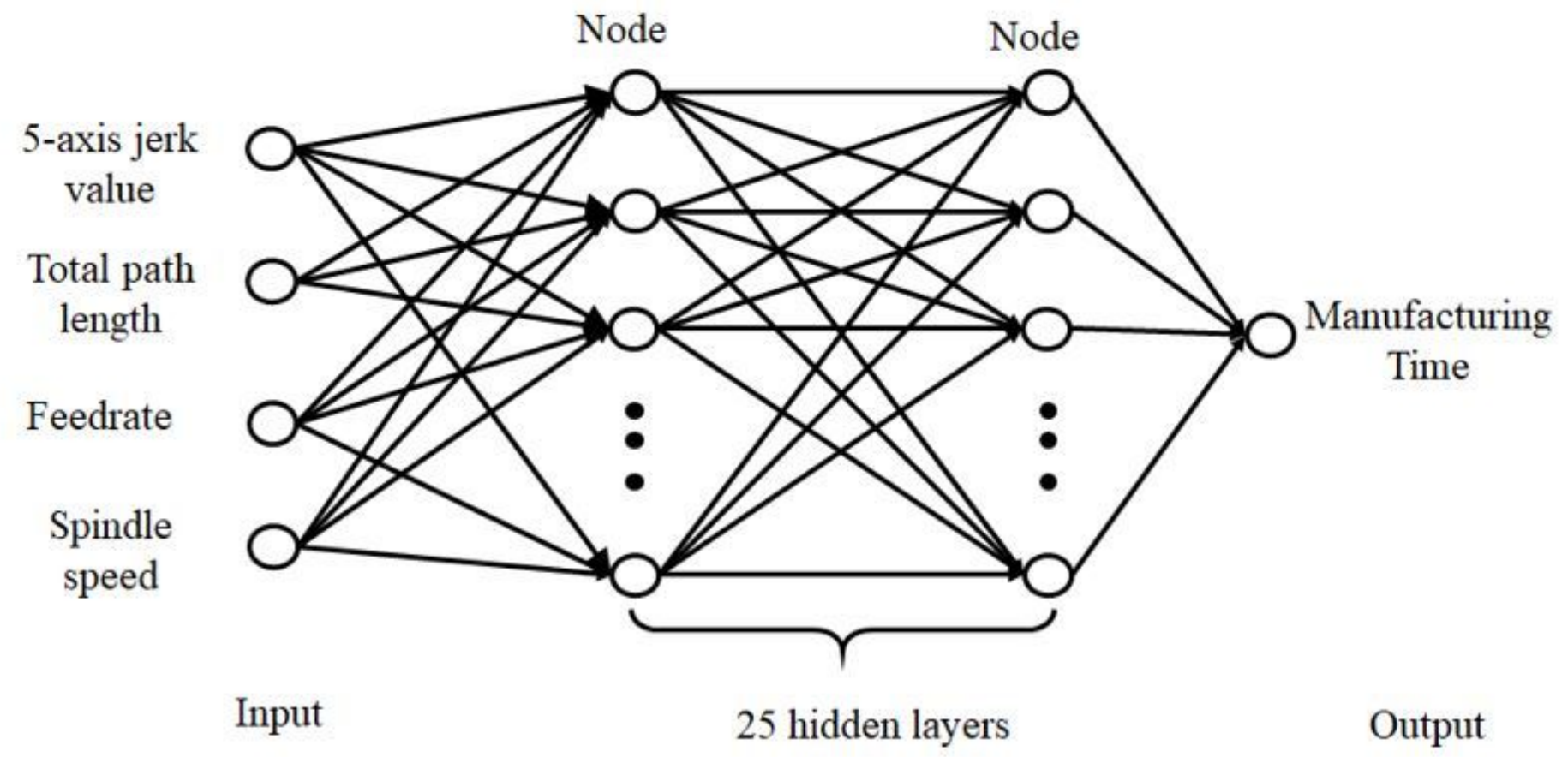

Figure 12

The machining time estimation model structure 


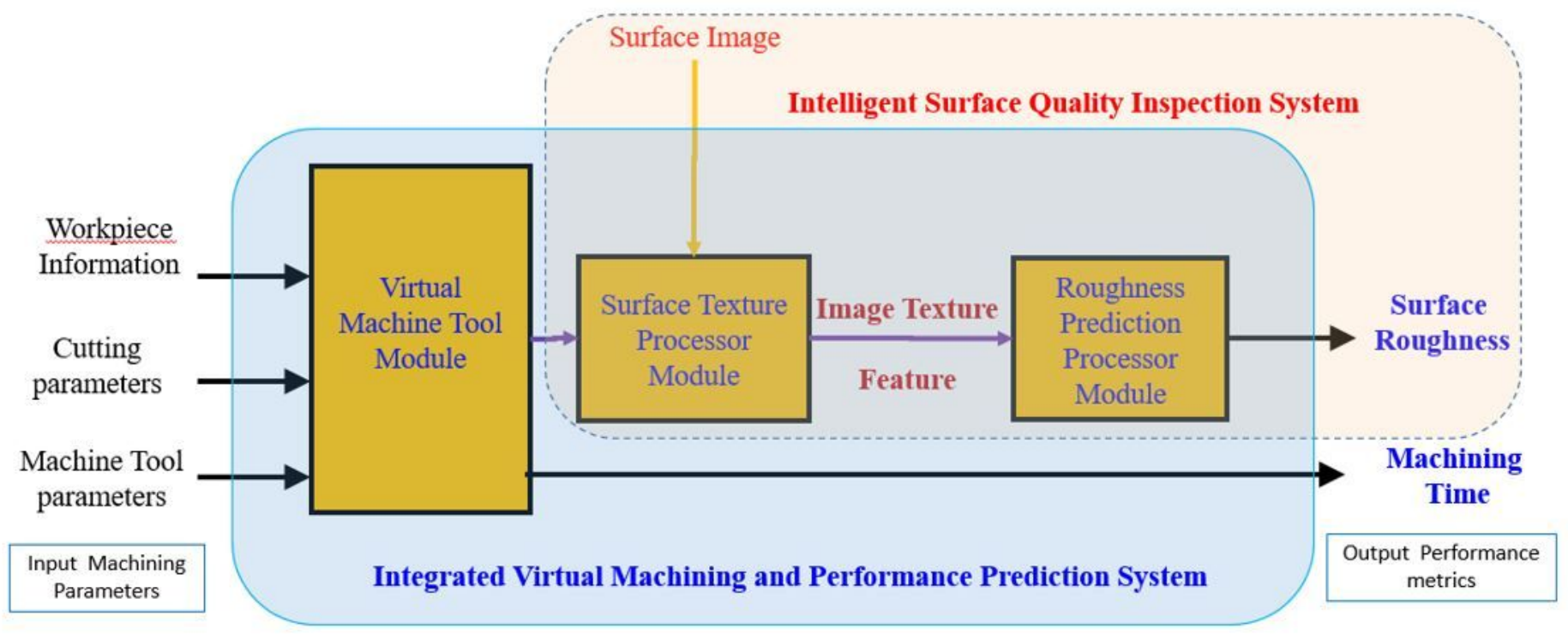

\section{Figure 13}

Integrated Performance Prediction System Diagram 